\title{
SCAPULAR SHAPE OF EXTANT HOMINOIDS AND THE AFRICAN APE/MODERN HUMAN LAST COMMON ANCESTOR
}

DAVID J. GREEN ${ }^{1,2,3 *}$, TED A. SPIEWAK ${ }^{1}$, BRIELLE SEITELMAN ${ }^{2}$, PHILIPP GUNZ ${ }^{4}$

${ }^{1}$ Chicago College of Osteopathic Medicine, ${ }^{2}$ Department of Anatomy, Midwestern University, $55531^{\text {st }}$ Street, Downers Grove, IL 60515, USA.

${ }^{3}$ Evolutionary Studies Institute and Centre for Excellence in PalaeoSciences, University of the Witwatersrand, Private Bag 3, Wits 2050, South Africa.

${ }^{4}$ Department of Human Evolution, Max Planck Institute, Deutscher Platz 6, 04103, Leipzig, Germany.

*corresponding author

email: dgreen1@ midwestern.edu

phone: 630-515-6062

fax: 630-515-7199 


\begin{abstract}
Newly discovered early hominin fossil scapulae have bolstered investigations of scapular shape, which have long been used to interpret behavioral variation among primates. However, unexpected similarities between Pongo and Homo - particularly in scapular spine orientation have raised questions about the functional utility of scapular morphology and its phylogenetic context in the hominin lineage. Not surprisingly, significant disagreement surrounds disparate morphological reconstructions of the modern human/African ape last common ancestor (LCA).

Our study utilizes geometric morphometric (GM) approaches - two employing homologous, anatomical landmarks in addition to a "spine-free" alternative using 98 sliding semilandmarks along the boundary of the subscapular fossa. The landmark-based "wireframe" GM analysis principally sorted groups by spine orientation: Homo and Pongo were similar to one another with more transversely-oriented spines as compared to Hylobates and the African apes. In contrast, Homo and Gorilla clustered together in our semilandmark analysis with superoinferiorly broad blades. Pan scapulae were similar, but had more mediolaterally compressed blades and laterally-positioned superior angles. Hylobates was superoinferiorly narrow, yet obliquely expanded relative to the vertebral border. Pongo scapulae were unique among hominoids in being nearly as broad as they were long.

Previously documented 'convergence' of Homo and Pongo scapulae seems to be principally driven by similarities in spine orientation, rather than overall blade shape. We thus contend that it is more parsimonious to reconstruct the African ape/Homo LCA scapula as being Gorilla-like, especially in light of similar characterizations of some fossil hominin scapulae. Accordingly, the evolution of Pan (highly oblique spine and laterally-situated superior angle) and Homo (transversely-oriented spine) scapular morphology would have involved relatively
\end{abstract}


minor shifts from this ancestral condition. These results support the prevailing molecular phylogeny and provide further insight into the behavioral implications of scapular shape in the LCA and fossil hominins.

Key words: Scapula, subscapular fossa, geometric morphometrics, hominoid, last common ancestor 


\section{Introduction}

The fossil record of early hominin scapulae has dramatically improved in both quantity and quality in the last ten years, given the extraordinary preservation of this fragile element from sites like Dikika (Alemseged et al., 2006), Woranso-Mille (Haile-Selassie et al., 2010), Malapa (Churchill et al., 2013), Dmanisi (Lordkipanidze et al., 2007), Flores (Larson et al., 2007, 2009), and Koobi Fora (Green et al., 2011). As scapular shape is commonly used to draw inferences about locomotor behavior in extinct taxa (Inman et al., 1944; Ashton and Oxnard, 1964; Oxnard, 1967; Roberts, 1974; Larson, 1995; Young, 2003, 2008; Bello-Hellegouarch et al., 2013; Green, 2013), these new fossils are welcome additions to the sparsely preserved record of this skeletal element. Although this material has afforded a richer view of early hominin scapular shape, in some ways, this information has engendered nearly as many questions about the evolution of hominoid scapular shape as it has answered.

Part of the problem stems from methodological issues surrounding the measurement and categorization of scapular shape. Much of the work seeking to characterize primate scapular shape has relied on traditional morphometric methods built from anatomical landmarks. More recent work has applied three-dimensional geometric morphometric (GM) methods to the study of scapular morphology (Taylor and Slice, 2005; Young, 2008; Melillo, 2011; BelloHellegouarch et al., 2013; Young et al., 2015), but most still rely on the same set of discrete, anatomical landmarks. Unfortunately, the scapular blade presents very few landmarks, thus limiting the resolution of these data, potentially aligning taxa erroneously, and clouding subtle features that might otherwise distinguish groups. Accordingly, assessments of hominoid scapular shape have been mixed; on the one hand, highly arboreal taxa like Hylobates are clearly distinguished from Homo, but gross similarities also exist between modern humans and Pongo, 
the most arboreal of all the great apes. Some attribute this convergence to the unique form of quadrumanous climbing exhibited by Pongo (Young, 2008; Green, 2013), but there is also reason to believe that methodological discrepancies are to blame.

One example of this problem relates to the orientation of the scapular spine, a feature that sets Homo apart from Hylobates and the African apes. Several scapular traits, like supraspinous and infraspinous fossa breadths, covary with spine orientation and similarly distinguish these groups. Qualitatively, Hylobates and Pan possess mediolaterally narrow scapulae relative to the superoinferior dimension (breadth), while Homo and Pongo scapulae appear mediolaterally expanded. Mediolateral scapular length is typically measured as the distance from the medial border to a lateral point, usually one along the glenoid margin (Shea, 1986). However, because the only landmark along the medial border is the point where the spine intersects it, this distance only returns a reasonable measure of mediolateral length if the spine is oriented transversely to the superoinferior dimension. In contrast to the qualitative observation, Hylobates has a far greater relative length for this distance than would be expected, while Homo and Pongo both have smaller values (Larson, 1998; Green, 2013). Clearly, this speaks more to the inferior placement of the spine/medial border intersection point and spine orientation than the mediolateral dimension of the scapular blade. Consequently, traits like scapular spine orientation have the effect of overshadowing other aspects of scapular shape that could promote misleading characterizations of interspecific shape variation.

Of course, there are other ways to estimate mediolateral scapular shape, including the angle formed by the axillary and medial borders (Green, 2013). However, the potentially confounding effect of spine orientation warrants an investigation of scapular shape in the absence of this feature. One way to do this is to evaluate subscapular fossa shape, which compels 
further investigation of the role played by the subscapularis muscle in primate locomotion. The dorsal rotator cuff muscles display an inconstant level of activity throughout a range of primate locomotor activities (Larson and Stern, 1986), but subscapularis is consistently recruited during climbing (Larson, 1988; Larson and Stern, 2013). Accordingly, Larson (1995) suggested that arboreal hominoids would display an expanded lateral portion of the subscapularis fossa inferior to the ventral "bar" of bone, indicative of an enlargement of the muscle beyond that which would correspond to the complimentary muscles on the dorsal side. Green (2013) found support for this hypothesis such that Hylobates and the African apes had the broadest lateral expansions, but Pongo did not significantly differ from Homo. Larson and Stern (1986) also noted that different portions of the subscapularis muscle are recruited for different tasks and that its shape may actually be the driving force behind dorsal scapular fossa variation, given its broad attachment site across the entirety of the scapular blade. Larson (1995) suggested that greater differentiation of subscapularis might be reflected in the morphology of its insertion site on the lesser tubercle of the humerus, namely, that it would be taller relative to its width in more arboreal taxa. As before, this relationship held true for the African apes and Hylobates relative to Homo, but the Pongo ratio was smaller than Homo, and the two were not significantly different (Green, 2013). Beyond this, relatively little attention has been paid to subscapular fossa shape relative to the dorsum of the scapula.

Larson and Stern (2013) and Larson (2015) recently investigated the relationship between muscle and fossa size, but found little association between scapular fossa size and physiological cross sectional area (PCSA), an important indicator of muscle force. Despite obvious differences in shape, rotator cuff muscle activity was generally conserved across the primate groups they considered, suggesting that changes in PCSA might have occurred to maintain functional 
equivalency despite gross shifts in fossa shape. What then, might have promoted these shape changes? Larson (2015) hypothesized that the dorsal position of the hominoid scapula (relative to the bone's more lateral position in monkeys) placed a greater emphasis on the role of scapular rotators like serratus anterior for forelimb elevation. Larson (2015) argued that hominoids have superoinferiorly broad scapulae to provide more area for serratus anterior to attach, particularly along the inferior margin of the scapula. Roberts (1974) also noted that dorsally-positioned, hominoid scapulae are mediolaterally narrower than those of monkeys to enable effective rotation without impacting the vertebral column. Reconfiguring a mediolaterally elongated, "monkey-shaped" scapula into a superoinferiorly broad, mediolaterally short ape scapula may have resulted in a shortening of the supraspinous fossa, but also a broadening of the infraspinous fossa (Larson, 2015). This shift may also be associated with a greater emphasis being placed on the role of the caudal portion of serratus anterior during suspensory activities (Larson et al., 1991). Changes to these larger muscle groups and their potential influence on scapular shape can be evaluated through additional study of subscapular fossa shape. If these larger muscle groups played a pivotal role in overall scapular shape, its relative position about the thorax, and the configuration of its fossae, we contend that subscapular fossa shape may similarly provide much needed information about biomechanical and functional demands placed on the upper limb.

Most scapular blade landmarks are located along its borders (e.g., suprascapular notch, superior angle, spine/medial border intersection point, inferior angle) and can be used to represent both dorsal and ventral aspects. However, since the spine/medial border intersection point represents spine orientation, including this point essentially nullifies the goal of focusing only on ventral scapular shape. Unfortunately, omitting this point means that the medial border would be represented as a straight line between the superior and inferior angles. Such a loss of 
morphological information could undermine the utility of the shape data, and so this study additionally utilizes semilandmarks to achieve greater coverage of subscapular fossa morphology (Bookstein, 1997a; Gunz et al., 2005; Perez et al., 2006). In cases where homologous landmarks are unavailable, one can compare homologous shapes by representing them as outlines or curves upon which a discrete set of equally-spaced semilandmarks may be assigned (Gunz and Mitteroecker, 2013). The curves are resampled so that the semilandmarks are equal in number and order across the sample. In this manner, semilandmarks can be used in lieu of static landmarks to satisfy the criterion of geometric correspondence for finer-grained shape comparisons (Gunz et al., 2005).

Both landmark and semilandmark data will be used in separate GM analyses to compare dorsal scapular and subscapular fossa shape, respectively. Our goal is to better understand the role that spine orientation plays in determining similarities among hominoid taxa, and how its "absence" influences these comparisons. If spine orientation was directly related to the frequency of climbing activities, one could posit that Pongo spines ought to be intermediate with respect to Hylobates and the African apes, since the African apes are the least arboreal of the non-human apes. Instead, Pongo scapular spine orientation is actually more transversely-oriented than the African apes (Green, 2013; Larson and Stern, 2013). Other studies have similarly identified aspects of scapular shape where Pongo aligns with modern humans or is at least intermediate with respect to the African apes in both two- and three-dimensional shape space (Green et al., 2015a, b). Not surprisingly, many fossil hominin scapulae also show morphological features that are intermediate between African apes and Homo, thus falling in a shape space similar to that occupied by Pongo (Melillo, 2011; Green and Alemseged, 2012; Churchill et al., 2013). This raises several questions related to both function and phylogeny: might fossil hominins have 
displayed a similar behavioral repertoire to modern Pongo? Would the scapular shape of the chimpanzee/modern human last common ancestor have been Pongo-like? How important are similarities in spine orientation from a functional standpoint if the trait is convergent in both highly arboreal and bipedal (non-arboreal) hominoids? To what extent might spine orientation be driving these similarities and does this trait cloud other potentially important scapular features?

We do not predict the results of our GM investigations to differ dramatically. However, any deviation from this null hypothesis will enable us to evaluate how spine orientation has influenced past comparisons. Since the wireframe and semilandmark datasets are distinct representations of scapular shape, we expect that the results of this study will enable us to better categorize the functional and potentially phylogenetic implications of previously noted similarities between Pongo and Homo.

\section{Materials and methods}

\section{Sample}

Individual belonging to dental stages 6 and 7 were considered to be adult, following the guidelines discussed in Shea (1981). The modern human sample was derived from both Native American and industrialized populations. The nonhuman sample included both mountain (Gorilla beringei) and western lowland (G. gorilla) gorillas; a majority of the gibbons were Hylobates lar (Table 1). Morphometric data were collected on scapulae from adult modern human (Homo sapiens), great ape (Pan troglodytes, G. gorilla, G. beringei, and Pongo pygmaeus), and lesser ape (Hylobates spp.) individuals. This study compares several threedimensional geometric morphometric approaches to investigating scapular and subscapular fossa 
shape with traditional, anatomical landmarks as well as computer-derived semilandmarks. All data were generated with an Immersion MicroScribe G2 digitizer (Fig. 1a; Table 2).

\section{INSERT FIGURE 1 and TABLES 1 and 2 HERE}

\section{Geometric morphometrics (GM) of scapular shape}

GM methods remove the effects of size and orientation to evaluate shape differences (Bookstein, 1997b; Zelditch et al., 2004; Slice, 2005). GM is particularly useful for comparing scapulae from either the right or left side and with landmarks collected using independently calibrated coordinate systems (so long as dimensions are held constant). Furthermore, this sample includes groups ranging from gibbons, which weigh only $10-11 \mathrm{~kg}$, to male gorillas that can be larger than $170 \mathrm{~kg}$; size would otherwise be the most influential factor contributing to the interspecific variance, potentially clouding other important aspects of shape difference. Procrustes superimposition and thin plate spline (TPS) interpolation are among the most commonly applied GM methods (Zelditch et al., 2004; Slice, 2005; Gunz et al., 2012). Objects are first scaled to the same centroid size, after which they are rotated and translated into a common position. TPS surface warps provide a way to visualize shape differences between one individual (target shape) and another or the "mean" shape. These warps can also be used to "exaggerate" shape changes to interpret how target shapes differ from the mean. This same process is utilized to interpolate semilandmarks along curves when homologous landmarks cannot be identified or if data is missing (Gunz et al., 2005, 2012; Gunz and Mitteroecker, 2013). Landmark-based GM of scapular shape The six landmarks listed in Table 2 provide a "wireframe" outline with which to perform a simple analysis of scapular shape (Fig. 1b). The decision to include point 3 (intersection of spine and medial border) was based on the fact that it is the only anatomical landmark available along this boundary. Point 6 (spinoglenoid notch) was 
included to make the wireframe depiction easier to interpret (i.e., it provided a point to connect with point 3 to represent the spine). Thus, including these points enables us to readily compare scapular shape both with the spine considered and in its absence. If points 3 and 6 were omitted, the medial boundary would be represented as a straight line between the superior and inferior angles. Although we suspect this would eliminate a significant amount of anatomical information along the medial border, we also considered this 4-point landmark representation as an alternative, "spine-free" characterization of scapular shape. Thus, the 6-point wireframe effectively investigates the shape of the dorsal scapular blade, whereas the 4-point wireframe and semilandmark analyses (outlined below) investigate the shape of the ventral blade. Semilandmark-based GM of subscapular shape The majority of the landmarks being utilized in the wireframe analyses are Type 2 or 3 landmarks (e.g., point 2, which is the maximum point of a curve, the superior angle [Bookstein, 1997b]), forcing one to relax the standards of biological and functional "homology" (Zelditch et al., 2004). As before, excluding these types of landmarks would further limit the morphological resolution and undermine the utility of the shape data. To overcome these limitations, a semilandmark approach was used to capture subscapular fossa shape. In cases where homologous landmarks are unavailable, one can compare homologous shapes by representing them as outlines or curves upon which a discrete set of semilandmarks may be assigned (Gunz and Mitteroecker, 2013). Using the "AutoPlot" setting of the MicroScribe, the digitizer stylus manually traced the border of the fossa, recording data at $1 \mathrm{~mm}$ intervals. After resampling curve lengths, 98 semilandmarks were evenly distributed along each curve. However, equally spacing the semilandmarks can result in warps with localized shape differences during Procrustes superimposition. To prevent these artificial transformations, equidistant semilandmarks were iteratively allowed to slide along the curve, so as to minimize 
the thin-plate spline bending energy between each specimen and the Procrustes average shape. During this procedure, semilandmarks slide along local tangents to the curve (as opposed to the curve itself), which makes the minimization of bending energy less computationally intensive. Semilandmarks are then projected back onto the curve following each sliding step to ensure that no semilandmarks slide "off" it, which would create visual artifacts unrelated to actual fossa morphology. Semilandmark sliding removes the effect from the initial spacing of the semilandmark coordinates, avoiding inappropriate transformations that could occur when analyzing equidistantly-spaced points (Gunz et al., 2005; Gunz and Mitteroecker, 2013). The resultant sets of semilandmarks are not only equal in number and order but also geometrically correspondent across the sample. Whereas only six static landmarks could be used to represent scapular blade shape in the wireframe analysis, now, 98 semilandmarks provide more complete coverage of overall blade shape (Fig. 1c).

Following Procrustes superimposition, both wireframe and semilandmark shape variables were used in separate principal component analyses (PCA) to evaluate differences across groups. In addition to the semilandmark PCA, a between-groups PCA was used to evaluate differences among groups. This technique is similar to a discriminant functions analysis (DFA) in identifying group affiliation a priori, but in this approach, the successive PC axes that best distinguish groups remain orthogonal to one another, as in a traditional PCA (and in contrast to DFA). Procrustes distances between group means were used to evaluate the significance of shape differences with permutation tests (as in Gunz et al., 2012). Distances were calculated and the grouping labels were randomly reassigned 2,000 times. $P$-values were calculated by dividing the number of times the scrambled Procrustes distances were greater than or equal to the actual 
between-group distance by 2,001 (the total number of permutations plus the original - e.g., if 20 of the permutations were greater than the actual distance, the $p$-value would be 0.01 ). Both Mathematica (Wolfram Research, Inc. 2013) and Morphologika (O'Higgins and Jones, 2006) software packages were used to generate the PCA graphs and visualize shape differences. Group means, represented as the average of the Procrustes shape coordinates and TPS interpolation, were used to compare extreme shape differences along the PC axes to the mean shape. The relative position of the groups in PC space can then be associated with shape changes along one or more PC axes. Differences in mean PC scores were assessed by one-way ANOVA and post-hoc Tukey Honest Significant Difference tests. These statistical analyses were performed in STATISTICA (StatSoft, 2014).

\section{Results}

"6-point wireframe" GM approach to scapular blade shape

Figures $1 \mathrm{~b}$ and 2 display the wireframe representation of the scapular blade. The first principal component of the wireframe Procrustes shape scores explained $61.1 \%$ of the variance in the sample. Homo and Pongo fell along the negative end of PC 1, while Hylobates had more positive PC 1 scores (Fig. 3). The African apes fell intermediately between these two groups, though Gorilla had fairly similar PC 1 scores to Pongo; Pan was slightly more positive. All mean PC 1 values were significantly different among taxa genera $(p<0.001$; Fig. 3$)$. Shape changes along PC 1 were primarily driven by spine orientation, the position of the spine/medial border intersection, and the relative positions of the superior angle and the suprascapular notch. The spine/medial border point occurs inferiorly in Hylobates, such that the extreme positive PC 1 shape has a spine that is nearly parallel to the axillary border. Conversely, Homo and Pongo have 
more transversely oriented spines, with the extreme position more closely approximating the orientation of the superior border.

\section{INSERT FIGURES 2 and 3 HERE}

The second PC explained $18 \%$ of the variance in the sample and primarily showcased differences in mediolateral length as well as superoinferior breadth of the blade (Fig. 2). The African apes fell along the positive end of the PC 2 axis with relatively broad, but short fossae, while Pongo clustered along the negative end of the axis with a blade that was roughly equal in breadth and length. Superior angle position in the African apes was also more prominent and laterally positioned, while it was more medially situated and closer to the spine/medial border intersection point in Pongo. Homo and Hylobates fell closer to the middle part of the axis, though Homo trended closer to the African ape shape; spine orientation was not a major factor discerning shape along PC 2 (Fig. 3). G. gorilla and G. beringei were not significantly different from one another for either of the PC axes, although G. beringei clustered among the Pan data within the broader Gorilla shape space (Fig. 2). As with PC 1, all mean PC 2 values were significantly different among taxa genera $(p<0.001$; Fig. 3$)$.

\section{Semilandmark GM approach to subscapular fossa shape}

Figures 1c and 4 depict the semilandmark (curve) representation of the subscapular fossa; a between-groups PCA found all genera to be significantly different from one another $(p<$ 0.001). As in the wireframe analysis, PC 1 (57.3\%) shape differences distinguished Homo and Hylobates along the negative and positive ends of this axis, respectively. Although this analysis did not consider the spine, the overall oblique orientation of the hylobatid scapular blade is evinced by the relatively short medial border and elongated axillary border (Fig. 4). In contrast, Homo, and notably Gorilla, possess scapulae that are much broader, superoinferiorly, with 
relatively short axillary borders. This gives the impression of a more lateral-facing scapular neck when the superior and inferior angles are aligned in the vertical plane (Fig. 4). Pongo and Pan fell intermediately along PC 1; Pan appeared to trend slightly more towards Gorilla and Homo, while the Pongo cluster was more positively situated.

\section{INSERT FIGURE 4 HERE}

The curve PC 2 (20.0\%) results were similar to those of the wireframe in most clearly separating Pan from Pongo in mediolateral width relative to superoinferior fossa height. However, data scatters were highly variable along PC 2 for most groups, such that Pongo was not significantly different from either Gorilla species (Fig. 5). Hylobates and Homo were not significantly different, with both taxa occupying the middle portion of PC 2 . Owing in part to the

small sample size, G. beringei was not significantly different from any of the taxa, save for Pan, which was significantly different from both Gorilla species along PC 2. This axis separated the more mediolaterally expanded Gorilla fossae from the constricted shape that categorizes Pan. While gross similarities in superior angle morphology aligned the African apes along PC 2 in the wireframe analysis, differences in gross blade shape distinguished Pan from Gorilla in the semilandmark analysis.

\section{INSERT FIGURE 5 HERE}

\section{“4-point wireframe” GM approach to scapular blade shape}

Figure 6 depicts the scapular blade as four points by eliminating points 3 and 6 from the original wireframe; this analysis produced results that were intermediate with respect to the two previous examples. Homo and Hylobates were again separated along the first PC axis, and Pongo individuals fell more positively and closer to Hylobates, as in the semilandmark analysis. Gorilla 
and Homo had the most negative PC 1 scores, while Pan was near the grand mean (Fig. 7). As before, PC 1 differentiated Homo and Hylobates with superoinferiorly broad and short blades, respectively, emphasizing that the superior angle of Homo (and Gorilla) rises significantly higher relative to the suprascapular notch than in Hylobates and to a lesser extent, Pongo.

\section{INSERT FIGURES 6 and 7 HERE}

As before, PC 2 differentiated the groups by mediolateral scapular blade dimensions, with Homo and Pongo sharing relatively wider blades (Fig. 6). Pan and Gorilla were more similar to one another (as they were in the 6-point wireframe analysis), owing in part to their more laterally-positioned superior angles. Hylobates also occupied a more positive position along PC 2. As before, Gorilla species were not significantly different along either of the two PC axes (Fig. 7).

\section{Discussion}

Both landmark and semilandmark GM analyses were performed to investigate subscapular fossa shape and general scapular blade shape, while also considering the influence of the scapular spine. The 4-point wireframe analysis was included to determine if a "spine-free" wireframe approach would match the results of a more exhaustive semilandmark depiction of the subscapular fossa. Although the results of these two analyses were similar in some respects, the oversimplification of the medial border in the 4-point wireframe trial produced notable differences in the location of the Gorilla data relative to Homo and Pan (Figs. 4 and 6). As such, the remainder of our discussion will focus on the differences between the 6-point wireframe and semilandmark depictions of scapular and subscapular shape. Mountain and lowland gorillas were considered separately despite the small sample of G. beringei. The species were not significantly 
different along any of the PC axes, but there was a clear trend for G. beringei to fall nearest to the Pan data. In addition, when there was significant overlap between Pan and Gorilla, G. beringei tended to fall within the Pan data (Figs. 2, 4, 6). This trend is worth pursuing with a larger sample, especially if similarities between G. beringei and Pan reflect their more arboreal tendencies relative to G. gorilla (Tocheri et al., 2011).

Our semilandmark analysis identified marked differences between Pongo and Homo while highlighting important similarities between Gorilla and Homo. Gorilla and Homo scapular blades are broadest superoinferiorly, with prominent superior angles that give the appearance of enlarged supraspinous fossae ${ }^{1}$. Pan displays a similar shape to Gorilla, and also Homo in some cases, but it also resembles Hylobates in possessing a more laterally positioned superior angle. For this reason, Pan morphology might be considered convergent with Hylobates, which is consistent with the fact that Pan is smaller and more arboreal than Gorilla. In contrast, the long axes of Hylobates and Pongo scapulae are more oblique with respect to the medial border, and the superior angle does not rise as prominently relative to the blade. To further illustrate these points, Figure 8 highlights a typical subscapular curve from each of the taxa considered. The superior angle is medially situated in Pongo, almost as in quadrupedal monkeys (see also Young, 2008), but it is more laterally situated in Hylobates. Despite these differences in superior angle morphology, both Hylobates and Pongo share a long, narrow supraspinous fossa (Green et al., 2015b). From the ventral view, however, the superior portions of the subscapular fossa are strikingly similar between these two taxa, which may account for the degree of overlap evident in Figure 4.

\section{INSERT FIGURE 8 HERE}

\footnotetext{
${ }^{1}$ Though the African ape/human supraspinous fossa appears broader with respect to Pongo, it may not offer a considerably larger surface area for the supraspinatus muscle. The Pongo supraspinous fossa apparently compensates for being superoinferiorly narrow by being mediolaterally long (Green et al., 2015b; Larson, 2015).
} 
Previously noted similarities between Homo and Pongo scapulae are evident in the wireframe analysis, despite dramatic behavioral differences and striking disparities in postcranial size and shape (Fig. 2). These results are comparable to those of previous studies (particularly Green et al., 2015a,b, and Young, 2015) in that Pongo and Homo clustered nearer to one another relative to Hylobates and the African apes. The differences between the wireframe and semilandmark results confirm the influence of spine orientation in considerations of scapular shape, especially given that Pongo has the least oblique spine orientation of the non-human hominoids (Green, 2013). This runs counter to our original prediction that both GM analyses would result in similar shape categorizations among the taxa. Furthermore, spine orientation appears to overshadow aspects of gross blade shape that are more clearly elucidated in the semilandmark analysis. To be sure, scapular spine orientation is an important discriminator of overall scapular shape; recently, Young et al. (2015) suggested that spine orientation is linked with blade shape, such that taxa with mediolaterally wider scapulae also have more transverselyoriented spines. However, our analysis highlights that two taxa with similar blade shapes (e.g., Gorilla and Homo) can also possess disparate spine configurations. Much in the same way - and despite similarities in spine orientation - our semilandmark results highlighted gross differences in blade shape between Pongo and Homo that run counter to previous appraisals of scapular shape in these taxa (e.g., Bello-Hellegouarch et al., 2013; Green, 2013). These results call into question the definitive link between blade shape and spine orientation, but beyond that, the vast differences in Pongo and Homo locomotor repertoires warrants a more thorough investigation into the link between behavior and scapular spine orientation.

Although Pongo is the most arboreal of the great apes, one possible explanation for this shape convergence with Homo emerges from the fact that Pongo practices a vastly different form 
of suspensory behavior than that of Hylobates or the African apes. In an earlier study, Young (2008) noted that Pongo scapulae were most similar to those of arboreal quadrupedal monkeys like Lagothrix. Accordingly, he proposed that the departure from the more typical hominoid scapular shape might correspond with the fact that both of these primates move through the trees by bridging between supports in a more deliberate manner (Thorpe and Crompton, 2005, 2006; Young, 2008). Furthermore, most monkey scapulae are mediolaterally long with more transversely-oriented spines. It follows then, that an analysis considering spine orientation would align Pongo with Homo, the hominoid taxon with the most transversely-oriented spines.

Similarly, the significance of the transverse orientation of modern human spines is not entirely clear either. The predominant primate spine configuration is a more transverse one, so it is plausible that the diminished role of climbing behaviors in later hominin evolution precluded the need to maintain the (presumably) primitive, oblique orientation. Bolstering this is the suggestion that the use of the upper limbs for manipulative behaviors would have been facilitated by a more transversely-oriented scapular spine (Larson, 1995; Green, 2013). Roach et al. (2013) suggested that shifts in glenoid fossa orientation from cranial to lateral may have improved overarm throwing performance in Homo erectus. Given that Green (2013) found spine and glenoid orientation to covary, selective pressures promoting a more lateralized glenoid might have also promoted a more transversely oriented spine. Thus, the modern human spine could have evolved through a combination of relaxed selective pressures for an obliquely oriented spine, and may have been initiated by the increased role of manipulative behaviors and tool use in the early hominin behavioral repertoire (Harmand et al., 2015; Skinner et al., 2015).

Another possible explanation for the transverse orientation in the Pongo spine relates to the action of the dorsal members of the rotator cuff and the spine's role in supporting the 
structural framework of the blade. Larson and Stern (2013) noted that Pan recruited the entire infraspinatus muscle during suspensory behaviors, but Pongo recruited only the lower portions. Since the Pan spine is so obliquely oriented, the infraspinous region is smaller. As such, Pongo essentially utilized only the portions of the infraspinatus that correspond with those of Pan during suspensory activities. Accordingly, Pongo did not recruit the more transversely-oriented fibers located nearest to the spine. Larson and Stern (2013: 401) hypothesized that superior portions of this muscle presented an "unfavorable line of action" for suspensory behaviors in Pongo, and were only active when the infraspinatus was recruited to maintain glenohumeral stability. If only the obliquely-oriented fibers are essential to suspensory behaviors - as in Panwhy wouldn’t Pongo benefit from a more obliquely oriented spine? Larson and Stern (2013) contend that this orientation is better suited for structural reinforcement of the Pongo scapula, but the authors did not offer further discussion as to why this configuration should characterize the Pongo scapula as apart from other arboreal hominoids. One could surmise that a transversely-oriented spine better reinforces the mediolaterally elongated Pongo scapula. However, the combination seen in Homo of a transversely oriented spine on a superoinferiorly broad blade weakens this argument (Green, 2013). Clearly, further experimentation and/or biomechanical testing is needed to examine whether scapular spine orientation serves more of a structural role than one dictating the line of action of the supraspinatus and infraspinatus muscles.

The gross blade shape similarities displayed by Gorilla and Homo, and to a lesser extent Pan, align with the molecular evidence of a monophyletic African ape/Homo clade (Bradley, 2008; Langergraber et al., 2012; Scally et al., 2012; Pozzi et al., 2014). As such, we contend that the general blade characteristics displayed by modern Gorilla represent a reasonable model for 
the configuration of the scapular blade of the African ape/human last common ancestor (ALCA) (Young et al., 2015). In addition to general blade shape features like expanded superoinferior breadth and superior angle prominence - which give the impression of relative mediolateral constriction - we also hypothesize that the ALCA scapula would have displayed an obliquely oriented spine and a cranially oriented glenoid fossa, both traits that are consistent with arboreal activities (Stern and Susman, 1983; Hunt, 1991; Susman and Stern, 1991; Larson, 1995; Green, 2013). Given that Gorilla and Pan both have obliquely oriented spines and cranially oriented glenoid fossae, it is parsimonious to hypothesize the scapula of the ALCA also possessed a similar configuration.

The extreme morphology of the Hylobates scapula makes it difficult to hypothesize whether the scapula of the hominoid LCA (HLCA) would have been similarly extreme or if this unique suite of characters is better explained as being autapomorphic among the lesser apes. More conservatively, we cannot rule out that the great ape LCA (GLCA) was essentially Pongolike. In fact, broad similarities in subscapular fossa shape between Hylobates and Pongo imply that some features held in common among the African apes and Homo evolved after the Pongo lineage split from that which gave rise to the African apes and Homo. Since the Pongo spine is intermediate between Homo and the African apes, the spine of the HLCA was likely to have been at least as obliquely oriented as in Pongo. If scapular spine orientation became extremely derived in the hylobatid lineage, a similar claim could be made for the panin lineage with respect to a CA with a more transverse spine orientation. Thus, variation in scapular spine orientation is a likely example of homoplasy (Larson, 1998; Wood and Harrison, 2011) and may relate to the more arboreal habits of Pan relative to Gorilla. Moreover, the similarities between Homo and Gorilla suggest that this blade shape is symplesiomorphic with respect to the African ape/Homo 
clade. If we also contend that the scapular spine of the ALCA was more obliquely oriented, a transversely oriented spine would have had to evolve separately in both the pongin and hominin lineages. Alternatively, if the ALCA were to have been more Pongo-like, wholesale shifts in the blade and/or spine configuration would have had to occur in each of the Gorilla, Pan, and Homo lineages. Thus, we propose that spinal modifications are more likely to have occurred in the evolutionary history of Homo relative to a more Gorilla-like ALCA.

Reconstructing the ALCA as Pongo-like might seem to be an implausible alternative hypothesis, but gross similarities among modern Pongo and Homo, as well as with some fossil hominin material, have motivated just such a proposal (Melillo, 2011). Lovejoy et al., (2009) suggested that the GLCA would have been more similar in postcranial morphology and behavior to Miocene apes based on the morphology of Ardipithecus ramidus and rejected modern chimpanzee morphology as a plausible analog for that of the ALCA. Miocene ape scapulae, like those of Proconsul and Nacholapithecus, are thought to have been most similar to arboreal monkeys (Senut et al., 2004; Young et al., 2015), just as similar claims have been put forth for the unusual anatomy of the Pongo scapula (Young, 2008). Though Ardipithecus does not preserve scapular remains, a Pongo-like ALCA scapula would seem to be more in line with Lovejoy et al.'s (2009) hypothesized ancestral state than one that is Gorilla-like. Studies of fossil hominin scapular morphology including Australopithecus afarensis (KSD-VP-1/1 [HaileSelassie et al., 2010; Melillo, 2011]; A.L. 288-1 and DIK-1-1 [Green and Alemseged, 2012]), A. africanus (Sts 7 [Vrba, 1979; Green and Alemseged, 2012] and Stw 162 [Green and Alemseged, 2012]), and A. sediba (MH2 [Churchill et al., 2013]) have shown their characteristics to be intermediate with respect to African apes and Homo. This might support the hypothesis of an African apelike ALCA, were it not for the fact that those analyses also found Pongo to occupy a 
similar shape space. However, we contend that Pongo-like characterizations of hominin scapular shape are clouded by the fact that fossil hominin scapular spines are intermediate in their orientation, as are the shape attributes that covary with it (e.g., supraspinous and infraspinous breadth). Our analysis of subscapular shape highlights important differences between the Hylobates/Pongo scapular shape and those of African apes and Homo, which may be indicative of deeper phylogenetic constraints.

Given the fossil evidence detailed in the past 5-10 years and the results outlined above, we present two alternative evolutionary scenarios within the commonly accepted hominoid phylogeny (Fig. 9). The first proposes that the hominoid LCA was essentially Pongo-like. Furthermore, previously described convergence between modern and fossil hominin scapulae with Pongo (Melillo, 2011; Green and Alemseged, 2012; Churchill et al., 2013) implies that the African ape/Homo and Pan/Homo LCAs were similarly Pongo-like (Fig. 9a). Alternative scenarios invoking autapomorphies and evolutionary reversals may be plausible, but are far less parsimonious. A Pongo-like ALCA necessitates fewer modifications to the spinal arrangement in the hominin lineage, but would require gross changes in blade shape among Homo, Gorilla, and Pan, with additional spinal changes in Gorilla and Pan. This makes the scenario in Figure 9a far less likely than the hypothesis outlined in Figure $9 \mathrm{~b}$.

\section{INSERT FIGURE 9 HERE}

In this second scenario, a more Gorilla-like shape evolves sometime between 12-16 Ma (Scally et al., 2012; Pozzi et al., 2014). One potential shortcoming of this hypothesis is the assumption that very little about scapular shape changed within the Gorilla lineage, but of course this is a conservative hypothesis and the ALCA very likely displayed a combination of traits unlike any hominoid alive today. Likewise, if the gorilla-like scapular shape of the ALCA was 
maintained, such that it also characterized the LCA of the Pan/Homo clade, it is not difficult to imagine how a modern Pan or Homo scapula might have evolved. On the one hand, the general blade shape of Pan becomes more compressed mediolaterally and the spine becomes more obliquely oriented. These shifts could be related to increased climbing behaviors in the Pan lineage and may account for some of its convergence with Hylobates. Alternatively, overall blade shape remained fairly unchanged in the hominin lineage, but the spine became less obliquely situated. As before, the gradual decrease of climbing activities and/or the selective pressures imposed by increased manipulative tasks and tool use could have additionally facilitated these shifts.

To be sure, it is inappropriate to presume that a modern taxon represents the "primitive" condition of any lineage (Lovejoy et al., 2009; White et al., 2015). Unfortunately, modern ape characteristics are often cited as being primitive when they are observed in fossil hominins. It is for this reason that the LCA of the Pan and Homo lineages is expected to have been more Panlike. However, there is good reason to hypothesize that certain unique characteristics of modern chimpanzees are derived with respect to both Gorilla and Homo, and that various aspects of Gorilla and Homo postcrania better represent the primitive condition than Pan (Drapeau and Ward, 2007; Rak et al., 2007; Haile-Selassie et al., 2012; Williams, 2012; Terhune et al., 2013; Almecija et al., 2015). Thus, it is reasonable to consider these taxa as better models for reconstructing the morphology of the ALCA than Pan. This may provide us with a better understanding of the primitive condition for which to determine the polarity of other postcranial traits in the fossil record. 


\section{Conclusion}

The results of this study highlight several important aspects of scapular morphology that align with the molecular phylogeny of hominoids and also point to potential shortcomings of some traditional scapular morphometric approaches. To be sure, these methods are useful for enumerating gross differences among groups, particularly when considering incomplete fossils (Larson, 2007; Haile-Selassie et al., 2010; Melillo, 2011; Green and Alemseged, 2012; Churchill et al., 2013). Nonetheless, this study has highlighted several important issues that may have led to imprecise assessments of scapular shape as it pertains to taxonomic relationships and evolutionary history. While the results of our semilandmark study might seem at odds with those of previous research, they are congruent with prevailing phylogenetic hypotheses. Furthermore, they contextualize some of the fossil evidence that has recently come to light. First, the gorillalike morphology of the A. afarensis specimen, DIK-1-1, indicates that much of its morphology suggests the maintenance of primitive features (Alemseged et al., 2006; Green and Alemseged, 2012; Young et al., 2015). Similar attributes have been suggested for other members of $A$. afarensis, including A.L. 288-1, and A. africanus (Sts 7 and Stw 162). In addition, some of the derived attributes of other fossils, like KSD-VP-1/1 and MH2 (e.g., more transverse spine orientation), could be indicative of a reasonable amount of variation within an evolving genus that lived for roughly 2.5 million years. Our initial impression of these fossils suggests that their subscapular fossa shape would fall within the Gorilla/Homo data cluster (Fig. 4; direct analysis of the more complete specimens is forthcoming). This lends further support to the proposal that this shape should be considered primitive for the Homo/Pan and African ape/Homo clades.

Questions about the locomotor habits of the African ape/Homo LCA and early hominins remain if we are to suppose their scapular shapes were similar to that of Gorilla. Modern gorillas 
are largely terrestrial and practice knuckle-walking, but are also competent climbers, even if this activity does not predominate their locomotor budget (Remis, 1995, 1998; Doran, 1997). However, because the body size of modern chimpanzees, humans, and early hominins was small to moderate, it seems reasonable to propose that the Pan/Homo LCA - and possibly the ALCA had a body size comparable to modern chimpanzees (Wrangham and Pilbeam, 2001; Grabowski et al., 2015). Even though we are not proposing major shifts in scapular shape in the Gorilla lineage, dramatic increases in body size and sexual dimorphism could be considered autapomorphic. An ALCA with a small to moderate body size might have displayed a greater commitment to suspensory activities than modern gorillas, such that the retention of certain scapular traits in extinct hominin taxa - along with small body size - would indicate a concomitant maintenance of these locomotor behaviors, as has been posited elsewhere (Stern and Susman, 1983; Susman and Stern, 1991; Stern, 2000; Alemseged et al., 2006; Green and Alemseged, 2012; Churchill et al., 2013). Much of the debate surrounding early hominin locomotor habits has centered on not just the manner in which we interpret primitive or derived traits with regard to functional utility, but also the identification of a trait as being "primitive" or "derived". Such a claim relies on not only knowing the derived form, but also the morphology of the last common ancestor (Latimer, 1991; Susman and Stern, 1991). The results of this study shed new light on the scapular form of the African ape/Homo LCA (and possibly that of Pan/Homo), which is critical for a better understanding of the phylogenetic and functional implications of known fossil hominin scapulae and those still to be discovered. 


\section{Acknowledgements}

We wish to acknowledge D. Hunt and L. Gordon (NMNH), E. Westwig, I. Tattersall, and G. Garcia (AMNH), J. Chupasko and M. Omura (MCZ), Y. Haile-Selassie and L. Jellema (CMNH), and M. Harman and A. Gill (PCM) for coordinating museum visits. We wish to thank J.M. Plavcan, the Associate Editor, and three anonymous reviewers for their encouraging and insightful comments; J. Krecioch kindly provided useful suggestions on an earlier draft of this manuscript. Finally, we thank Midwestern University’s Dr. Kenneth A. Suarez Fellowship Program, the National Science Foundation IGERT grant (9987590), NSF Doctoral Dissertation Improvement Grant (BCS-0824552), and the Wenner-Gren Foundation for funding support. 


\section{References}

Alemseged, Z., Spoor, F., Kimbel, W.H., Bobe, R., Geraads, D., Reed, D., Wynn, J.G., 2006. A juvenile early hominin skeleton from Dikika, Ethiopia. Nature 443, 296-301.

Almecija, S., Smaers, J.B., Jungers, W.L., 2015. The evolution of human and ape hand proportions. Nat. Commun. 6, 7717.

Ashton, E.H., Oxnard, C.E., 1964. Functional adaptations in the primate shoulder girdle. Proc. Zool. Soc. Lond. 142, 49-66.

Bello-Hellegouarch, G., Potau, J.M., Arias-Martorell, J., Pastor, J.F., Perez-Perez, A., 2013. A comparison of qualitative and quantitative methodological approaches to characterizing the dorsal side of the scapula in hominoidea and its relationship to locomotion. Int. J. Primatol. 34, 315-336.

Bookstein, F.L., 1997a. Landmark methods for forms without landmarks: morphometrics of group differences in outline shape. Med. Image Anal. 1, 225-243.

Bookstein, F.L., 1997b. Morphometric Tools for Landmark Data: Geometry and Biology. Cambridge University Press, Cambridge.

Bradley, B.J., 2008. Reconstructing phylogenies and phenotypes: a molecular view of human evolution. J. Anat. 212, 337-353.

Churchill, S.E., Holliday, T.W., Carlson, K.J., Jashashvili, T., Macias, M.E., Mathews, S., Sparling, T.L., Schmid, P., de Ruiter, D.J., Berger, L.R., 2013. The upper limb of Australopithecus sediba. Science 340, 1233477.

Doran, D.M., 1997. Ontogeny of locomotion in mountain gorillas and chimpanzees. J. Hum. Evol. 32, 323-344.

Drapeau, M.S., Ward, C.V., 2007. Forelimb segment length proportions in extant hominoids and Australopithecus afarensis. Am. J. Phys. Anthropol. 132, 327-343.

Grabowski, M., Hatala, K.G., Jungers, W.L., Richmond, B.G., 2015. Body mass estimates of hominin fossils and the evolution of human body size. J. Hum. Evol. 85, 75-93.

Green, D.J., 2013. Ontogeny of the hominoid scapula: The influence of locomotion on morphology. Am. J. Phys. Anthropol. 152, 239-260.

Green, D.J., Alemseged, Z., 2012. Australopithecus afarensis scapular ontogeny, function, and the role of climbing in human evolution. Science 338, 514-517.

Green, D.J., Richmond, B.G., Harris, J.W.K., Mbua, E., Braun, D.R., Griffin, N.L., Chirchir, H., 2011. A new 1.5 Ma hominin scapula from Koobi Fora, Kenya. Am. J. Phys. Anthropol. $144,149$.

Green, D.J., Serrins, J.D., Seitelman, B., Martiny, A.R., Gunz, P., 2015a. Geometric morphometrics of hominoid infraspinous fossa shape. Anat. Rec. (Hoboken) 298, 180194.

Green, D.J., Sugiura, Y., Seitelman, B.C., Gunz, P., 2015b. Reconciling the convergence of supraspinous fossa shape among hominoids in light of locomotor differences. Am. J. Phys. Anthropol. 156, 498-510.

Gunz, P., Mitteroecker, P., 2013. Semilandmarks: a method for quantifying curves and surfaces. Hystrix 24, 103-109.

Gunz, P., Mitteroecker, P., Bookstein, F.L., 2005. Semilandmarks in three dimensions. In: Slice, D.E. (Ed.), Modern Morphometrics in Physical Anthropology. Kluwer Academic/Plenum, New York, pp. 73-98. 
Gunz, P., Ramsier, M., Kuhrig, M., Hublin, J.J., Spoor, F., 2012. The mammalian bony labyrinth reconsidered, introducing a comprehensive geometric morphometric approach. J. Anat. 220, 529-543.

Haile-Selassie, Y., Latimer, B.M., Alene, M., Deino, A.L., Gibert, L., Melillo, S.M., Saylor, B.Z., Scott, G.R., Lovejoy, C.O., 2010. An early Australopithecus afarensis postcranium from Woranso-Mille, Ethiopia. Proc. Natl. Acad. Sci. 107, 12121-12126.

Haile-Selassie, Y., Saylor, B.Z., Deino, A., Levin, N.E., Alene, M., Latimer, B.M., 2012. A new hominin foot from Ethiopia shows multiple Pliocene bipedal adaptations. Nature 483, 565-569.

Harmand, S., Lewis, J.E., Feibel, C.S., Lepre, C.J., Prat, S., Lenoble, A., Boes, X., Quinn, R.L., Brenet, M., Arroyo, A., Taylor, N., Clement, S., Daver, G., Brugal, J.P., Leakey, L., Mortlock, R.A., Wright, J.D., Lokorodi, S., Kirwa, C., Kent, D.V., Roche, H., 2015. 3.3million-year-old stone tools from Lomekwi 3, West Turkana, Kenya. Nature 521, 310315.

Hunt, K.D., 1991. Mechanical implications of chimpanzee positional behavior. Am. J. Phys. Anthropol. 86, 521-536.

Inman, V., Saunders, J., Abbott, L., 1944. Observations on the function of the shoulder joint. J. Bone Joint Surg. Am. 26, 1-30.

Langergraber, K.E., Prufer, K., Rowney, C., Boesch, C., Crockford, C., Fawcett, K., Inoue, E., Inoue-Muruyama, M., Mitani, J.C., Muller, M.N., Robbins, M.M., Schubert, G., Stoinski, T.S., Viola, B., Watts, D., Wittig, R.M., Wrangham, R.W., Zuberbuhler, K., Paabo, S., Vigilant, L., 2012. Generation times in wild chimpanzees and gorillas suggest earlier divergence times in great ape and human evolution. Proc. Natl. Acad. Sci. 109, 1571615721.

Larson, S.G., 1988. Subscapularis function in gibbons and chimpanzees: implications for interpretation of humeral head torsion in hominoids. Am. J. Phys. Anthropol. 76, 449462.

Larson, S.G., 1995. New characters for the functional interpretation of primate scapulae and proximal humeri. Am. J. phys. Anthrop. 98, 13-35.

Larson, S.G., 1998. Parallel evolution in the hominoid trunk and forelimb. Evol. Anthropol. 6, 87-99.

Larson, S.G., 2007. Evolutionary transformation of the hominin shoulder. Evol. Anthropol. 16, 172-187.

Larson, S.G., 2015. Rotator cuff muscle size and the interpretation of scapular shape in primates. J. Hum. Evol. 80, 96-106.

Larson, S.G., Stern, J.T., Jr., 1986. EMG of scapulohumeral muscles in the chimpanzee during reaching and "arboreal" locomotion. Am. J. Anat. 176, 171-190.

Larson, S.G., Stern, J.T., Jr., 2013. Rotator cuff muscle function and its relation to scapular morphology in apes. J. Hum. Evol. 65, 391-403.

Larson, S.G., Stern, J.T., Jr., Jungers, W.L., 1991. EMG of serratus anterior and trapezius in the chimpanzee: scapular rotators revisited. Am. J. Phys. Anthropol. 85, 71-84.

Larson, S.G., Jungers, W.L., Morwood, M.J., Sutikna, T., Jatmiko, Saptomo, E.W., Due, R.A., Djubiantono, T., 2007. Homo floresiensis and the evolution of the hominin shoulder. J. Hum. Evol. 53, 718-731. 
Larson, S.G., Jungers, W.L., Tocheri, M.W., Orr, C.M., Morwood, M.J., Sutikna, T., Awe, R.D., Djubiantono, T., 2009. Descriptions of the upper limb skeleton of Homo floresiensis. J. Hum. Evol. 57, 555-570.

Latimer, B., 1991. Locomotor adaptations in Australopithecus afarensis: the issue of arboreality. In: Coppens, Y., Senut, B. (Eds.), Origine(s) de la Bipédie chez les Hominidés. CNRS, Paris, pp. 169-176.

Lordkipanidze, D., Jashashvili, T., Vekua, A., Ponce de Leon, M.S., Zollikofer, C.P., Rightmire, G.P., Pontzer, H., Ferring, R., Oms, O., Tappen, M., Bukhsianidze, M., Agusti, J., Kahlke, R., Kiladze, G., Martinez-Navarro, B., Mouskhelishvili, A., Nioradze, M., Rook, L., 2007. Postcranial evidence from early Homo from Dmanisi, Georgia. Nature 449, 305-310.

Lovejoy, C.O., Suwa, G., Simpson, S.W., Matternes, J.H., White, T.D., 2009. The great divides: Ardipithecus ramidus reveals the postcrania of our last common ancestors with African apes. Science 326, 100-106.

Melillo, S.M., 2011. Anatomy of the Australopithecus scapula and evolution of the human shoulder: insights from a new fossil specimen, KSD-VP-1/1G. Ph.D. Dissertation, Stanford University.

O'Higgins, P., Jones, N., 2006. Tools for statistical shape analysis. Hull York Medical School. http://sites.google.com/site/hymsfme/resources.

Oxnard, C.E., 1967. The functional morphology of the primate shoulder as revealed by comparative anatomical, osteometric and discriminant function techniques. Am. J. Phys Anthropol. 26, 219-240.

Perez, S.I., Bernal, V., Gonzalez, P.N., 2006. Differences between sliding semi-landmark methods in geometric morphometrics, with an application to human craniofacial and dental variation. J. Anat. 208, 769-784.

Pozzi, L., Hodgson, J.A., Burrell, A.S., Sterner, K.N., Raaum, R.L., Disotell, T.R., 2014. Primate phylogenetic relationships and divergence dates inferred from complete mitochondrial genomes. Mol. Phylogenet. Evol. 75, 165-183.

Rak, Y., Ginzburg, A., Geffen, E., 2007. Gorilla-like anatomy on Australopithecus afarensis mandibles suggests Au. afarensis link to robust australopiths. Proc. Natl. Acad. Sci.104, 6568-6572.

Remis, M., 1995. Effects of body size and social context on the arboreal activities of lowland gorillas in the Central African Republic. Am. J. Phys Anthropol. 97, 413-433.

Remis, M.J., 1998. The gorilla paradox: the effects of body size and habitat on the positional behavior of lowland mountain gorillas. , In: Strasser, E., Fleagle, J.G.H., Rosenberger, A., McHenry, H.M. (Eds.), Primate Locomotion, Recent Advances. Plenum Press, New York, pp. 95-106.

Roach, N.T., Venkadesan, M., Rainbow, M.J., Lieberman, D.E., 2013. Elastic energy storage in the shoulder and the evolution of high-speed throwing in Homo. Nature 498, 483-486.

Roberts, D., 1974. Structure and function of the primate scapula. In: Jenkins, F.A. (Ed.), Primate Locomotion. Academic Press, New York, pp. 171-200.

Scally, A., Dutheil, J.Y., Hillier, L.W., Jordan, G.E., Goodhead, I., Herrero, J., Hobolth, A., Lappalainen, T., Mailund, T., Marques-Bonet, T., McCarthy, S., Montgomery, S.H., Schwalie, P.C., Tang, Y.A., Ward, M.C., Xue, Y., Yngvadottir, B., Alkan, C., Andersen, L.N., Ayub, Q., Ball, E.V., Beal, K., Bradley, B.J., Chen, Y., Clee, C.M., Fitzgerald, S., Graves, T.A., Gu, Y., Heath, P., Heger, A., Karakoc, E., Kolb-Kokocinski, A., Laird, 
G.K., Lunter, G., Meader, S., Mort, M., Mullikin, J.C., Munch, K., O'Connor, T.D., Phillips, A.D., Prado-Martinez, J., Rogers, A.S., Sajjadian, S., Schmidt, D., Shaw, K., Simpson, J.T., Stenson, P.D., Turner, D.J., Vigilant, L., Vilella, A.J., Whitener, W., Zhu, B., Cooper, D.N., de Jong, P., Dermitzakis, E.T., Eichler, E.E., Flicek, P., Goldman, N., Mundy, N.I., Ning, Z., Odom, D.T., Ponting, C.P., Quail, M.A., Ryder, O.A., Searle, S.M., Warren, W.C., Wilson, R.K., Schierup, M.H., Rogers, J., Tyler-Smith, C., Durbin, R., 2012. Insights into hominid evolution from the gorilla genome sequence. Nature 483, $169-175$.

Schuenke, M., Schulte, E., Schumacher, U., Ross, L.M., Lamperti, E.D., 2007. Thieme Atlas of Anatomy: General Anatomy and Musculoskeletal System. Thieme Medical Publishers, New York, NY.

Senut, B., Nakatsukasa, M., Kunimatsu, Y., Nakano, Y., Takano, T., Tsujikawa, H., Shimizu, D., Kagaya, M., Ishida, H., 2004. Preliminary analysis of Nacholapithecus scapula and clavicle from Nachola, Kenya. Primates 45, 97-104.

Shea, B.T., 1981. Relative growth of the limbs and trunk in the African apes. Am. J. Phys. Anthropol. 56, 179-201.

Shea, B.T., 1986. Scapula form and locomotion in chimpanzee evolution. Am. J. Phys. Anthropol. 70, 475-488.

Skinner, M.M., Stephens, N.B., Tsegai, Z.J., Foote, A.C., Nguyen, N.H., Gross, T., Pahr, D.H., Hublin, J.J., Kivell, T.L., 2015. Human-like hand use in Australopithecus africanus. Science 347, 395-399.

Slice, D.E., 2005. Modern morphometrics. In: Slice, D.E. (Ed.), Modern Morphometrics in Physical Anthropology. Kluwer Academic/ Plenum, New York, pp. 1-45.

StatSoft, I., 2014. STATISTICA (data analysis software system, ver. 12 ed.).

Stern, J.T., 2000. Climbing to the top: a personal memoir of Australopithecus afarensis. Evol. Anthrop. 9, 113-133.

Stern, J.T., Susman, R.L., 1983. The locomotor anatomy of Austalopithecus afarensis. Am. J. phys. Anthropol. 60, 279-317.

Susman, R.L., Stern, J.T., 1991. Locomotor behavior of early hominids: Epistemology and fossil evidence. In: Coppens, Y., Senut, B. (Eds.), Origine(s) de la Bipédie chez les Hominidés. CNRS, Paris, pp. 121-131.

Taylor, A.B., Slice, D.E., 2005. A geometric morphometric assessment of the relationship between scapular variation and locomotion in African apes. In: Slice, D.E. (Ed.), Modern Morphometrics in Physical Anthropology. Kluwer Academic/Plenum, New York, pp. 299-318.

Terhune, C.E., Kimbel, W.H., Lockwood, C.A., 2013. Postnatal temporal bone ontogeny in Pan, Gorilla, and Homo, and the implications for temporal bone ontogeny in Australopithecus afarensis. Am. J. Phys. Anthropol. 151, 630-642.

Thorpe, S.K., Crompton, R.H., 2005. Locomotor ecology of wild orangutans (Pongo pygmaeus abelii) in the Gunung Leuser Ecosystem, Sumatra, Indonesia: a multivariate analysis using log-linear modelling. Am. J. Phys. Anthropol. 127, 58-78.

Thorpe, S.K., Crompton, R.H., 2006. Orangutan positional behavior and the nature of arboreal locomotion in Hominoidea. Am. J. Phys. Anthropol. 131, 384-401.

Tocheri, M.W., Solhan, C.R., Orr, C.M., Femiani, J., Frohlich, B., Groves, C.P., Harcourt-Smith, W.E., Richmond, B.G., Shoelson, B., Jungers, W.L., 2011. Ecological divergence and medial cuneiform morphology in gorillas. J. Hum. Evol. 60, 171-184. 
Vrba, E.S., 1979. A new study of the scapula of Australopithecus africanus from Sterkfontein. Am. J. Phys. Anthropol. 51, 117-130.

White, T.D., Lovejoy, C.O., Asfaw, B., Carlson, J.P., Suwa, G., 2015. Neither chimpanzee nor human, Ardipithecus reveals the surprising ancestry of both. Proc. Natl. Acad. Sci. 112, 4877-4884.

Williams, S.A., 2012. Variation in anthropoid vertebral formulae: implications for homology and homoplasy in hominoid evolution. J. Exp. Zool. Part B. 318, 134-147.

Wolfram Research, I., Inc. 2013. Mathematica Edition: Version 9.0.1. Wolfram Reasearch, Inc., Champaign, IL.

Wood, B., Harrison, T., 2011. The evolutionary context of the first hominins. Nature 470, 347352.

Wrangham, R.W., Pilbeam, D., 2001. African apes as time machines.In: Galdikas, B.M.F., Briggs, N.E., Sheeran, L.K., Shapiro, G.L., Goodall, J. (Eds.), All Apes Great and Small Volume 1: African Apes. Kluwer Academic/Plenum Publishers, New York, pp. 5-17.

Young, N.M., 2003. A reassessment of living hominoid postcranial variability: implications for ape evolution. J. Hum. Evol. 45, 441-464.

Young, N.M., 2008. A comparison of the ontogeny of shape variation in the anthropoid scapula: Functional and phylogenetic signal. Am. J. Phys. Anthropol. 136, 247-264.

Young, N.M., Capellini, T.D., Roach, N.T., Alemseged, Z., 2015. Fossil hominin shoulders support an African ape-like last common ancestor of humans and chimpanzees. Proc. Natl. Acad. Sci. 112, 11829-11834.

Zelditch, M.L., Swiderski, D.L., Sheets, H.D., Fink, W.L., 2004. Geometric Morphometrics for Biologists: A Primer. Elsevier, San Diego, CA. 


\section{Figure legends}

Figure 1. a) Scapular landmarks used in this study (image modified from Schuenke et al. [2007]); see Table 2 for full list of landmarks. b) Wireframe and (c) semilandmark representations of scapular and subscapular fossa shape, respectively. The "spine line" is shadowed in gray in the ventral view of the wireframe in (b). The location of the three anchor points are depicted in Roman numerals in (c).

Figure 2. PCA of wireframe Procrustes shape coordinates. Red wireframe images at the zero point of each PC axis represent the mean shape; black, warped images represent extreme wireframe target shapes along the respective PC axes. Homo and Hylobates are distinguished along the first PC axis, which primarily distinguished taxa with transversely oriented spines from those with more oblique orientations. Notably, Pongo and Homo cluster near one another along this axis. PC 2 depicts major differences in superoinferior scapular dimensions, distinguishing the African apes and Homo from Pongo.

Figure 3. Boxplots depicting range of PC scores for the wireframe PCA depicted in Figure 2 top plots, PC1, bottom plots, PC 2. Tables below the graphs depict average PC distance among the taxa (values above the diagonal) and $p$-values (below the diagonal).

Figure 4. PCA of semilandmark Procrustes shape coordinates. Red curve images at the zero point of each PC axis represent the mean shape; black, warped images represent extreme subscapular fossa curve target shapes along the respective PC axes. As in the wireframe analysis, PC 1 largely distinguishes Homo from Hylobates, but Pongo is also shifted more towards the positive 
end of the axis with a more superoinferiorly compressed blade. Notably, the Homo and Gorilla data scatters overlap for both PC 1 and PC 2, indicating similar blade shapes when not accounting for spine orientation.

Figure 5. Boxplots depicting range of PC scores for the semilandmark PCA - top plots, PC1, bottom plots, PC 2. Tables below the graphs depict average PC distance among the taxa (values above the diagonal) and $p$-values (below the diagonal).

Figure 6. PCA of the 4-point wireframe Procrustes shape coordinates. Red wireframe images at the zero point of each PC axis represent the mean shape; black, warped images represent extreme target shapes along the respective PC axes. The results of this analysis were similar to the semilandmark analysis for PC 1 (Fig. 4), but the Gorilla data are shifted more intermediately with respect to Pan and Homo for PC 2. In this respect, the results were more like those of the 6point wireframe (Fig. 2), possibly indicating a loss of resolution when omitting significant anatomical detail.

Figure 7. Boxplots depicting range of PC scores for the 4-point wireframe PCA - top plots, PC1, bottom plots, PC 2. Tables below the graphs depict average PC distance among the taxa (values above the diagonal) and $p$-values (below the diagonal).

Figure 8. Semilandmark PCA plot with actual, representative individuals highlighted. Individuals were selected from those near the mean of each data ellipse. The target shapes highlighted in 
Figure 4 are extreme shapes that highlight the principle features that change along each PC axis. Accordingly, the extreme shape may not be representative of actual individuals in the sample.

Figure 9. Depiction of alternative evolutionary scenarios within the commonly accepted phylogenetic hypothesis: a) depicts the LCA as having a Pongo-like scapular shape, b) depicts an African ape/Homo LCA with a Gorilla-like scapular shape. See the text for further discussion. Divergent date ranges derived from Pozzi et al. (2014). 
Table 1. Sample size.

\section{Female Male Unknown Total}

\section{Taxon}

Pan troglodytes

Gorilla spp.

G. gorilla

G. beringei

Pongo pygmaeus

Hylobates spp.

H. lar
H. hoolock

H. agilis

H. concolor

H. klossii

Homo sapiens
25

26

21

5

28

31

20

7

3

1

0

24
32

27

24

3

16

25

18

5

0

2

0

30
2

2

2

0

3

4

60

39

13

4

3

1

Data were collected from specimens housed at the National Museum of Natural History

(Washington, DC), the American Museum of Natural History (New York City), the Cleveland Museum of Natural History (Ohio), the Museum of Comparative Zoology (Cambridge, MA), and the Powell Cotton Museum (Birchington, UK). 
Table 2. Scapular landmarks.

1 - Suprascapular notch - inferior-most point of the notch; if no true notch is present, this point was taken as the minimum point of curvature on the superior border, just medial to coracoid process

2 - Superior angle - the superior-most point of the scapula with the superior and inferior angles in line with imaginary vertebral column

3 - Spine / medial border intersection point (if the spine diminished before intersecting with the vertebral border, this point was selected as the intersection between the vertebral border and a straight line from the spinoglenoid notch through to the medial edge of the spine)

4 - Inferior angle - the inferior-most point of the scapula with the superior and inferior angles in line with an imaginary vertebral column

5 - Infraglenoid tubercle - inferomedial to the glenoid fossa, the origin site of the triceps brachii muscle 6 - Spinoglenoid notch - the point where the base of the spine meets the blade inferior to the junction of the spine and the acromion See also Figure 1a. 

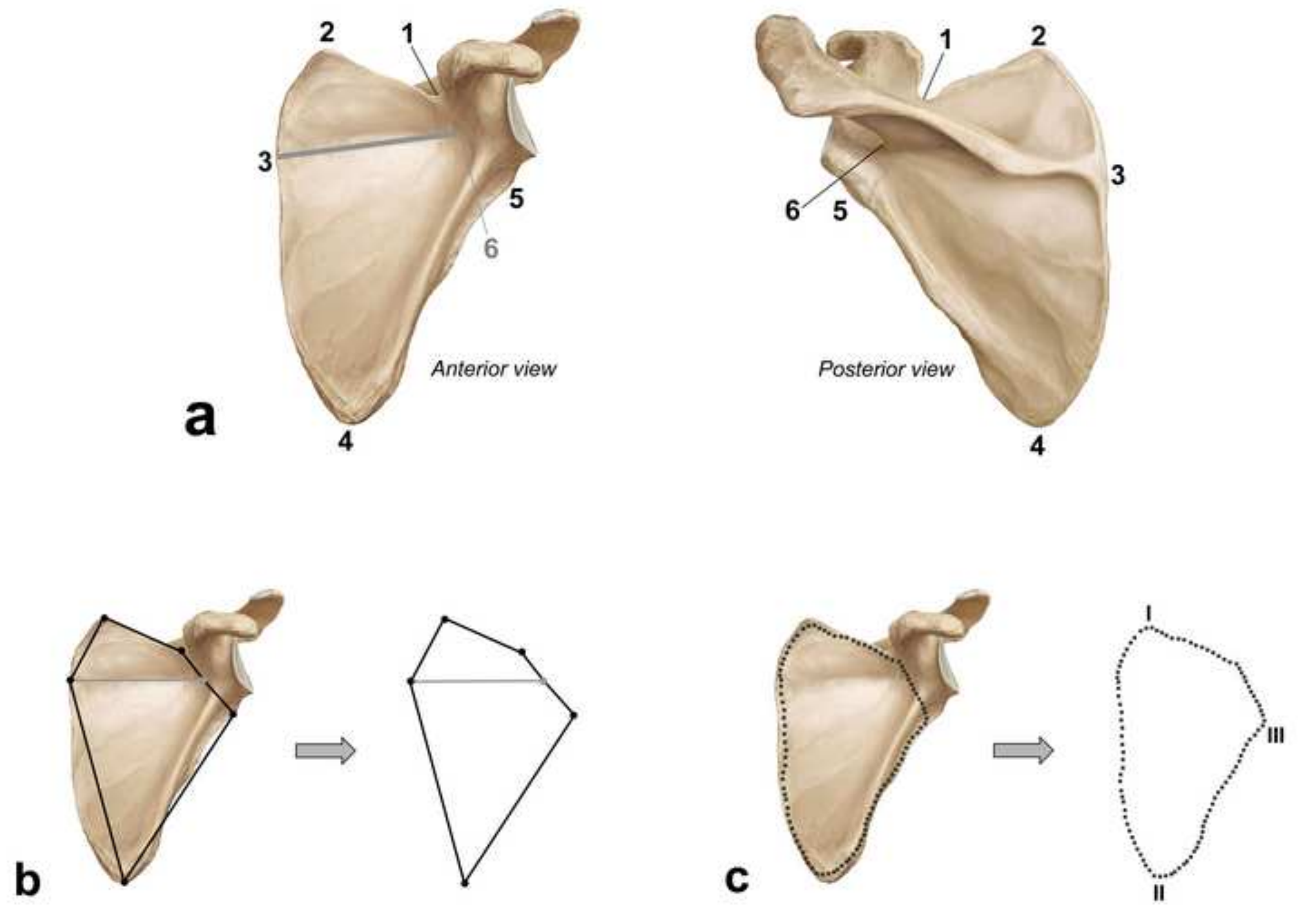


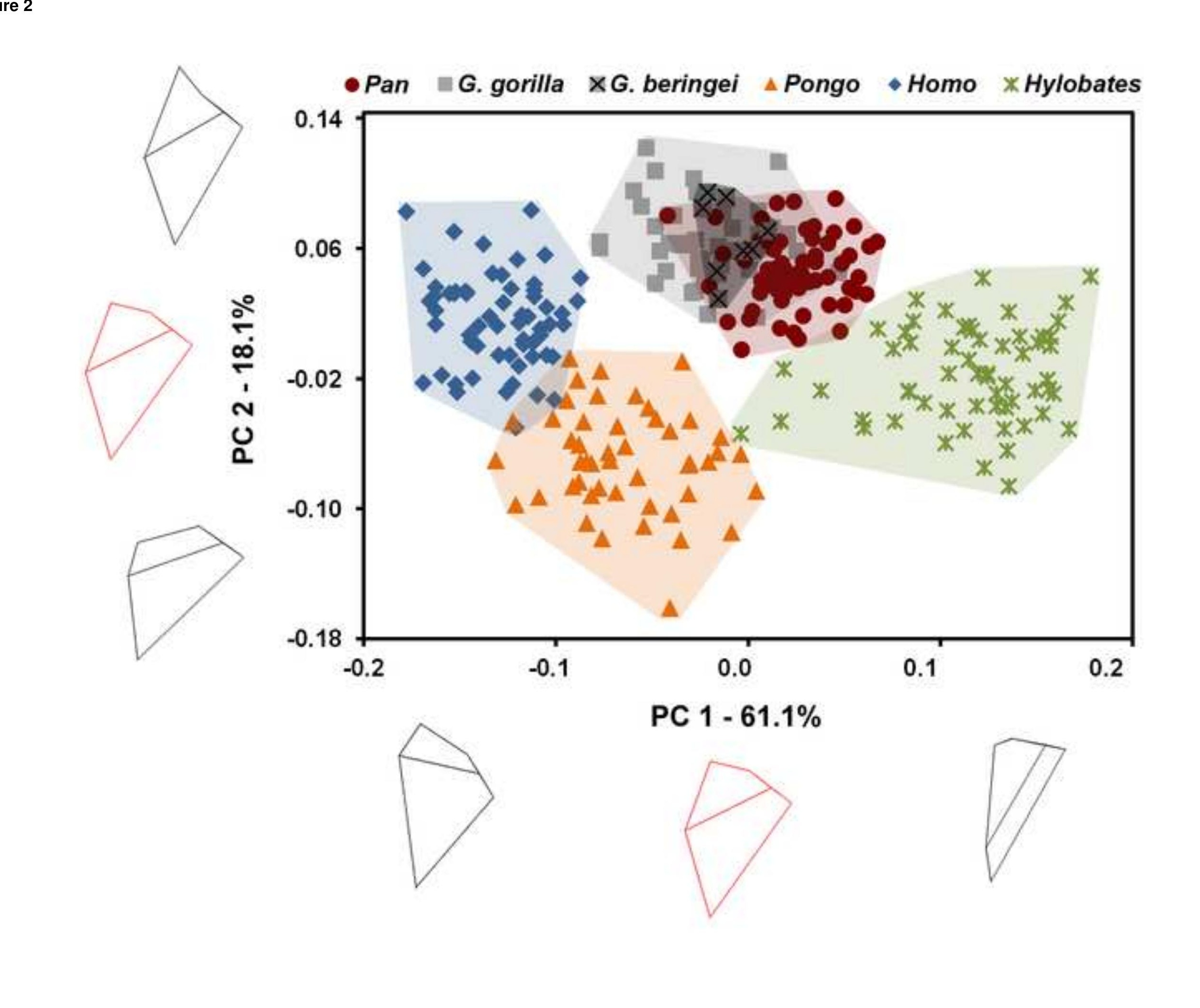

.

.

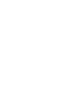

\section{Figre

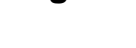

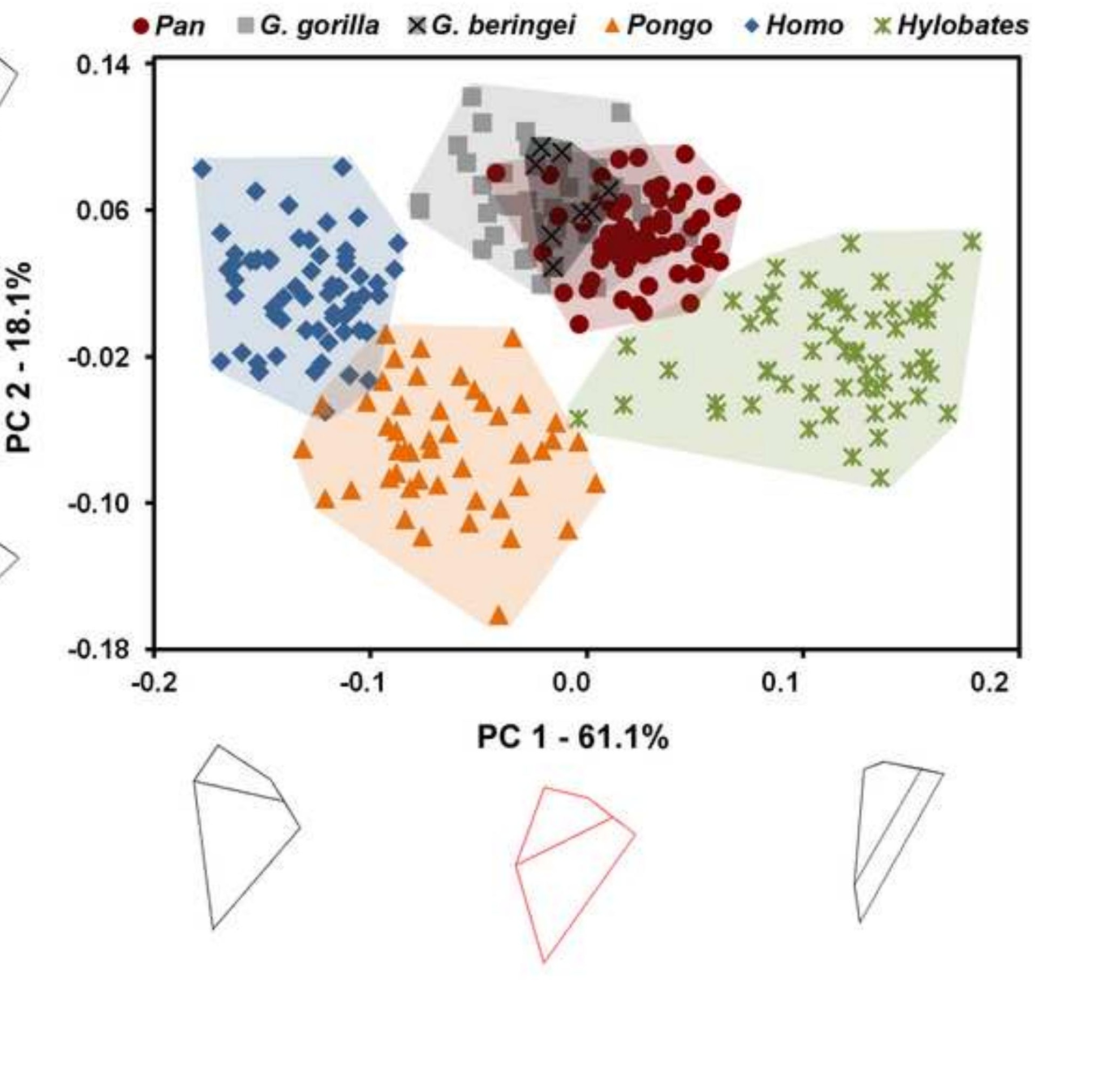


Figure 3
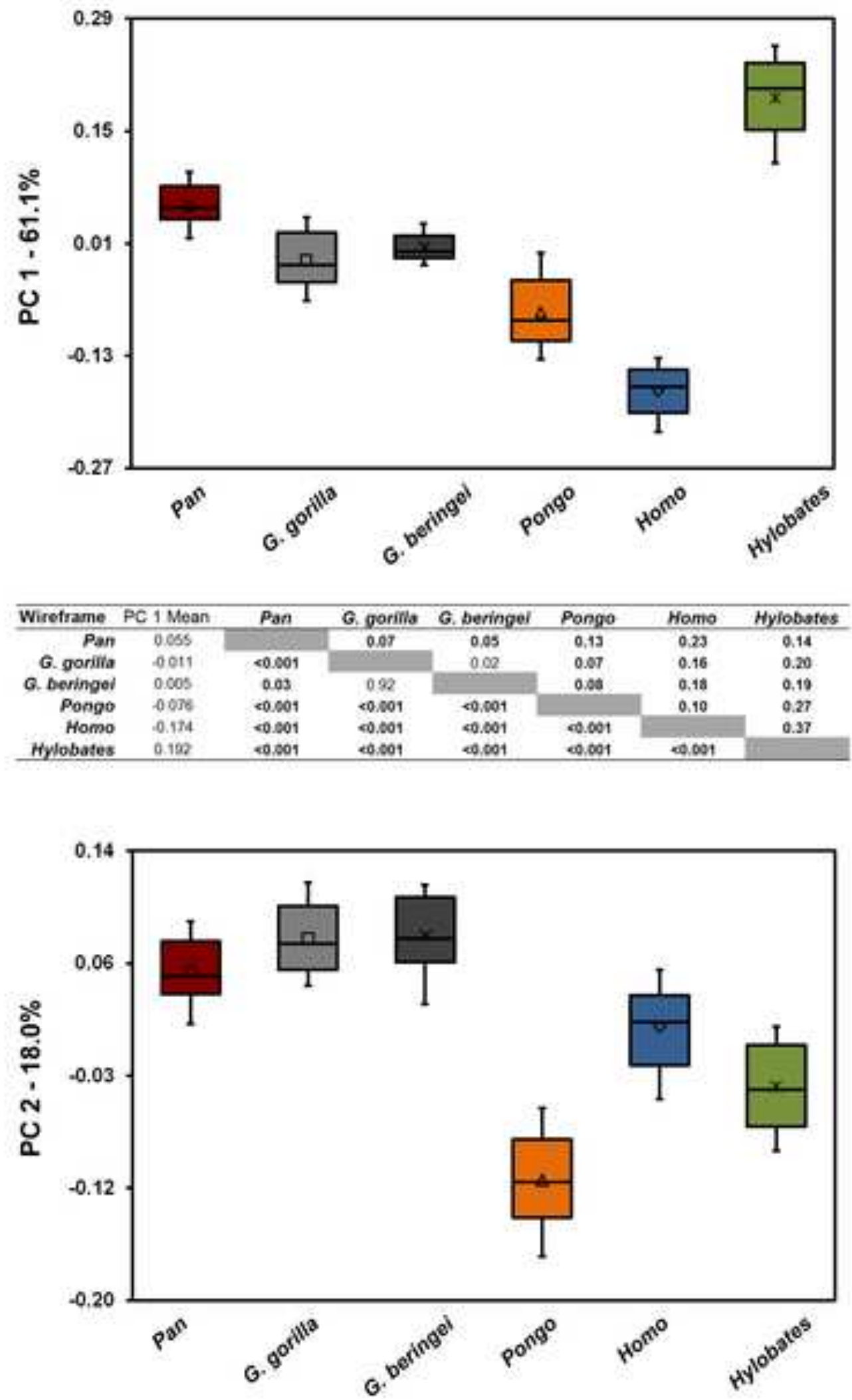

\begin{tabular}{|c|c|c|c|c|c|c|c|}
\hline Wireframe & PC 2 Mcan & Pan & c. gorilla & a, beringed & Pongo & Howno & Hylobates \\
\hline Pan & 0.049 & & 0.03 & 003 & 0.16 & 0.04 & 0.09 \\
\hline G. gorilla & 0074 & 0.005 & & 0.002 & 0.58 & 0.07 & a.t1 \\
\hline G. beringei & 0076 & 0.35 & 1.00 & & 0.19 & $0.0 \%$ & 0.51 \\
\hline Pango & 0.109 & coboot & $<0.001$ & 60.004 & & 0,22 & 0.07 \\
\hline Hamo & 0.007 & $=0.001$ & $<0.001$ & $<0.001$ & $<0.001$ & & 0.05 \\
\hline Hylobates & .0038 & $<0.005$ & $<0.001$ & $<0.001$ & $<0.001$ & 60,601 & \\
\hline
\end{tabular}




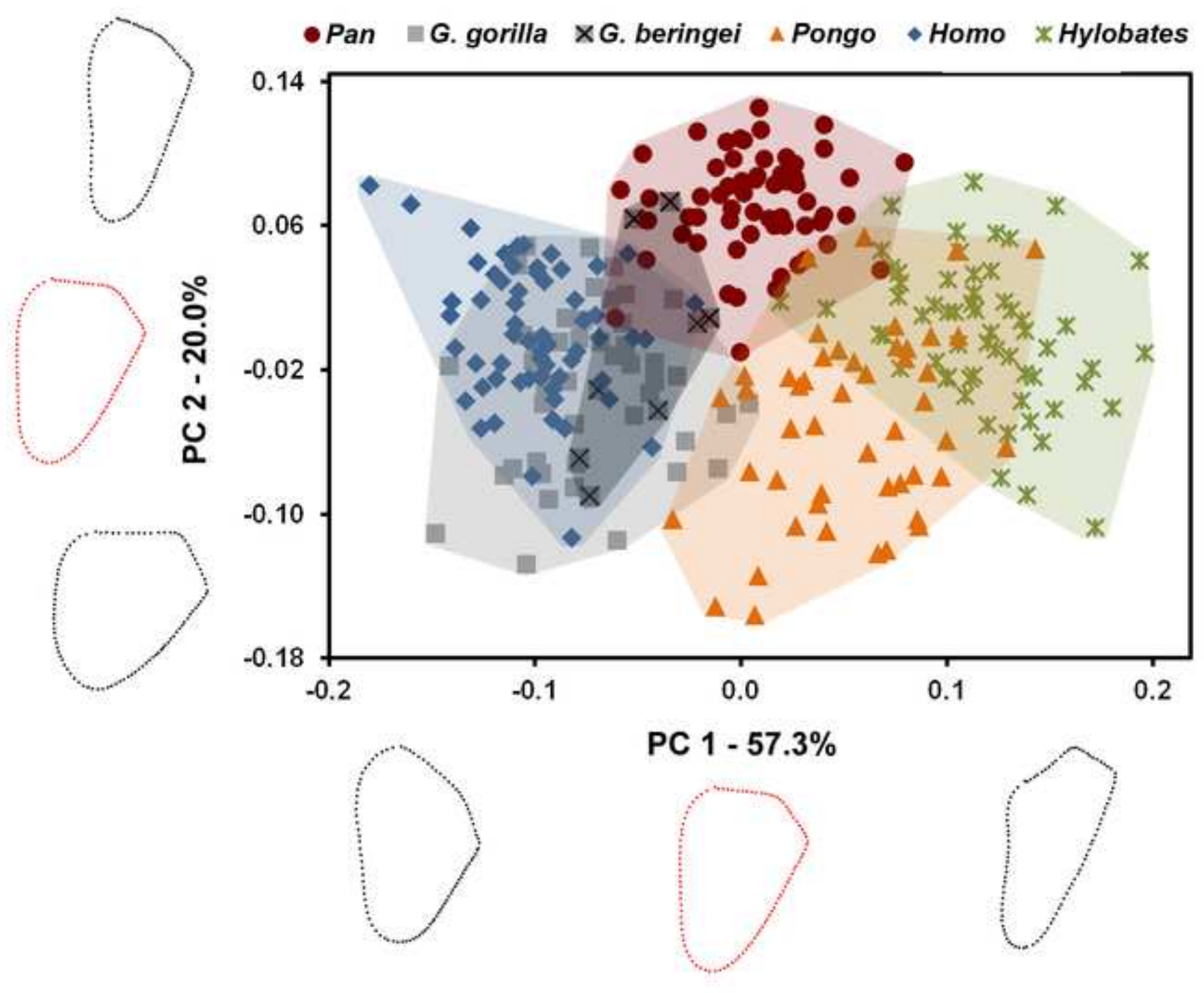


Figure 5

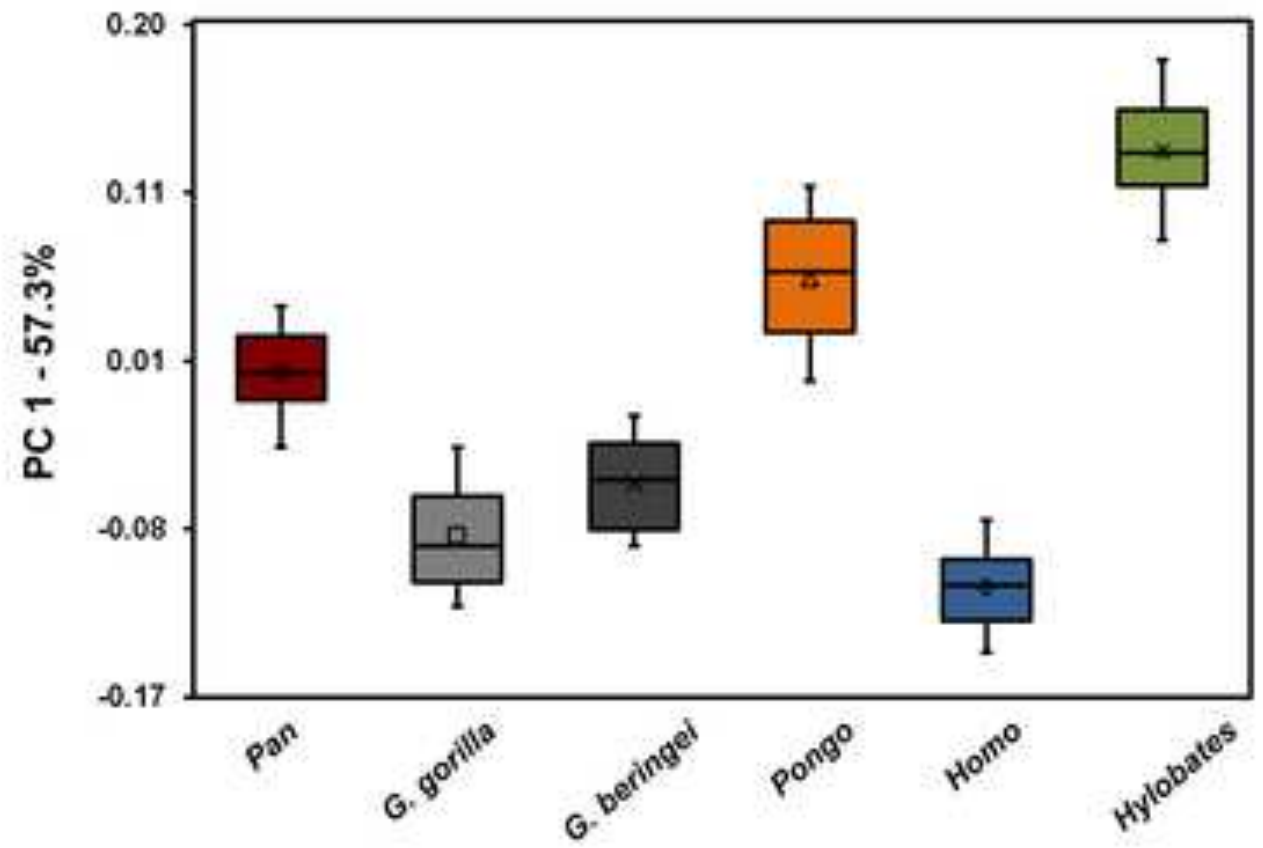

\begin{tabular}{|c|c|c|c|c|c|c|c|}
\hline Curve & PC 1 Mean & Pan & G. porifis & G. beringel & Pongo & Homo & Hyiobafes \\
\hline Pan & 0.007 & & 0.59 & 0.86 & 0.05 & 0.12 & 0.12 \\
\hline G. gorilla & 0 on 2 & $\infty .001$ & & 0.00 & 0.14 & 0.09 & 0.21 \\
\hline Q. Beringev & .0 .083 & $\bullet 0,001$ & 0.29 & & 0.11 & 0,04 & 0.13 \\
\hline Pongo & 0049 & $<0.001$ & $<0.001$ & $\infty, 001$ & & 0.17 & 6.07 \\
\hline Homo & .0 .110 & $\infty .001$ & $\infty 0.001$ & $\infty, \infty 01$ & 60.001 & & 0.24 \\
\hline Hylobafes & 0.129 & 00.001 & $e 0.001$ & 20.001 & $\infty .001$ & Q9.06t & \\
\hline
\end{tabular}

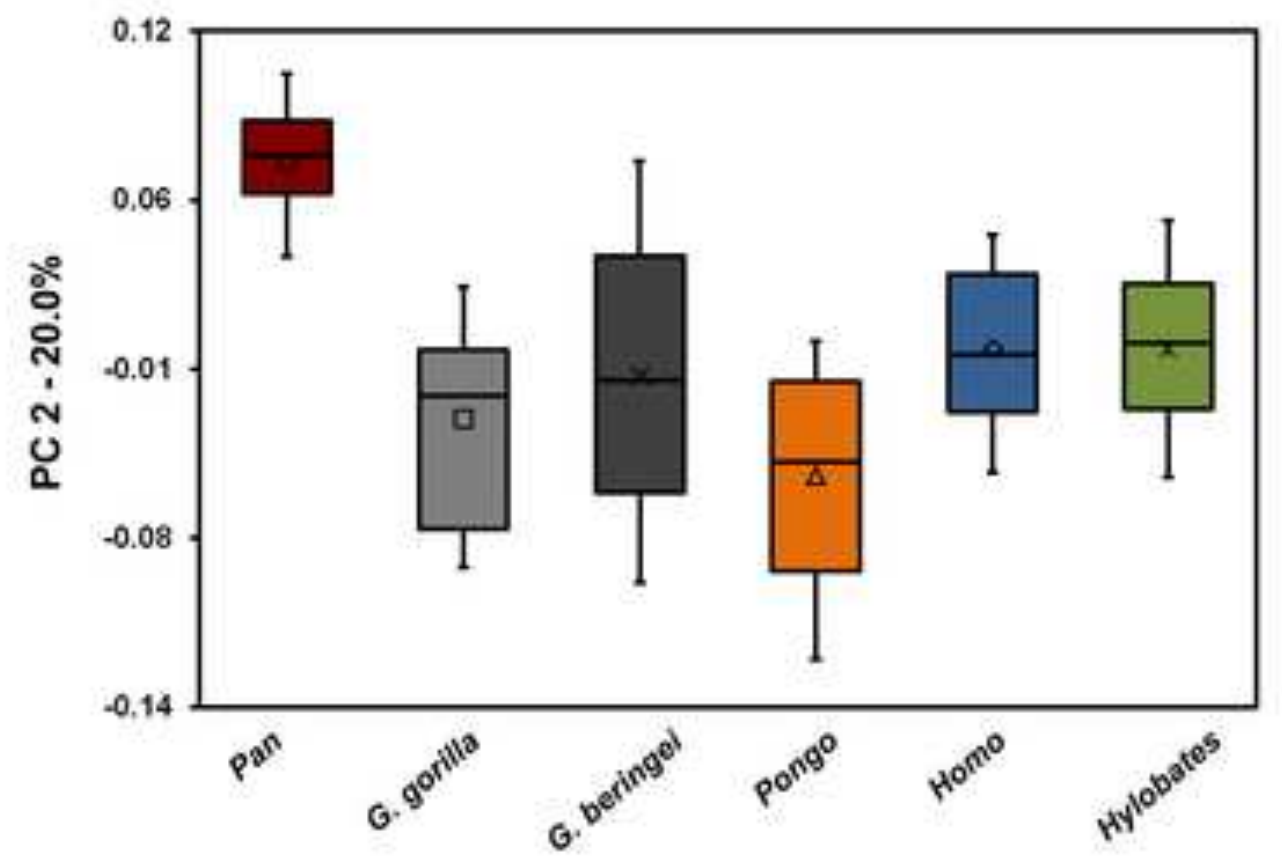

\begin{tabular}{|c|c|c|c|c|c|c|c|}
\hline Curve & PC 2 Moan & Pan & Q, gorilla & G. beringel & Pongo & Homo & Hylobates \\
\hline Pan & 0,069 & & a.10 & 6.08 & 6.12 & 0.07 & 0.07 \\
\hline G. goollia & .0020 & $<b .001$ & & 002 & 0.02 & 0.03 & 0.03. \\
\hline o. beringed & .0012 & .0 .001 & 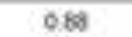 & & 004 & 001 & 001 \\
\hline Pongo & .0051 & $\circ 0.001$ & 0.09 & 0.12 & & 0.05 & 0.05 \\
\hline Homo & 0.002 & 06.001 & 0.007 & ose & $<0001$ & & 000 \\
\hline Hylobates & -0002 & -0.001 & copost & 098 & $<0.005$ & 100 & \\
\hline
\end{tabular}




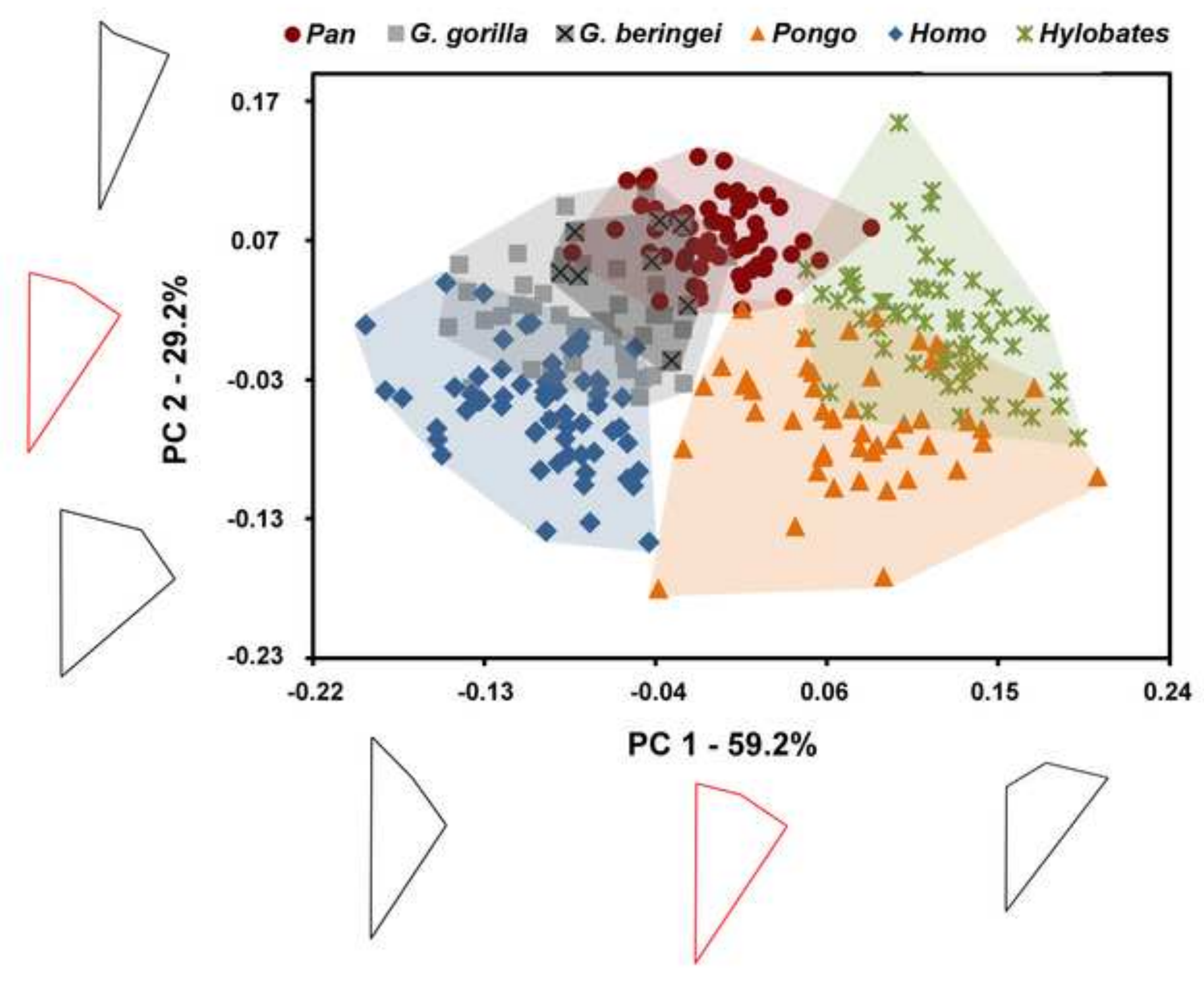


Figure 7

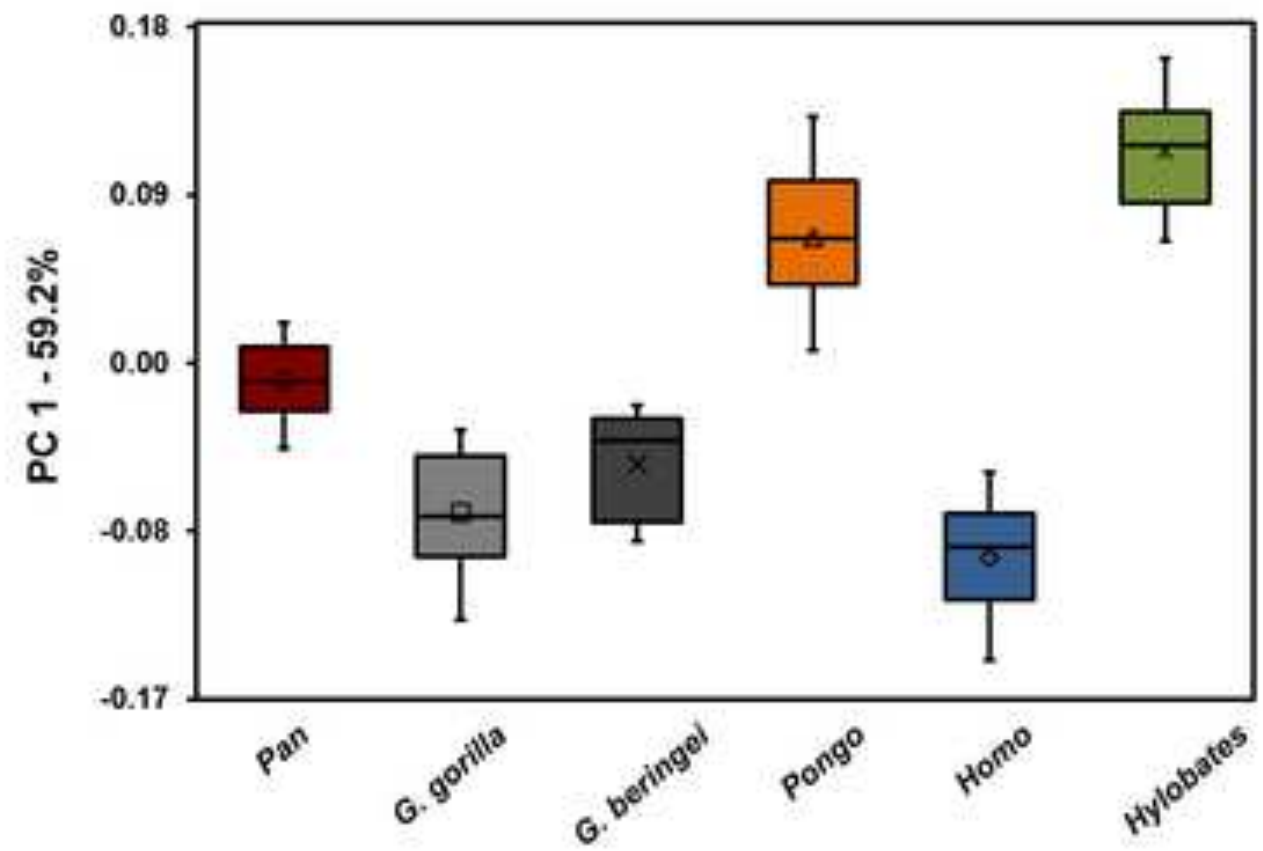

\begin{tabular}{|c|c|c|c|c|c|c|c|}
\hline 4 pt. Wire & PC 1 Mean & Pan & G. gorifla & G. beringel & Pango & Homo & Hyfobstes \\
\hline Pan & -0005 & 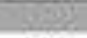 & 0.07 & 0.04 & 0.07 & 0.00 & 0.12 \\
\hline G. gorifla & $00 \mathrm{Cr}$ & $<0.601$ & & 0.03. & 0.14 & 0.02 & 0.19 \\
\hline Q. beringel & -0.043 & 0.02 & 0.45 & & 0.12 & 0.05 & 0.16 \\
\hline Pongo & $0 \not 00$ & $<0.001$ & $<0,201$ & $<0.001$ & & 0.17 & 0.04 \\
\hline Homo & .0097 & $<0.001$ & 0.01 & 0,004 & 00.001 & & $0.2 \mathrm{~s}$ \\
\hline Hylobates & $0.1 t 4$ & $<0,001$ & $<0.001$ & 20.001 & $\infty, 001$ & 09.001 & \\
\hline
\end{tabular}

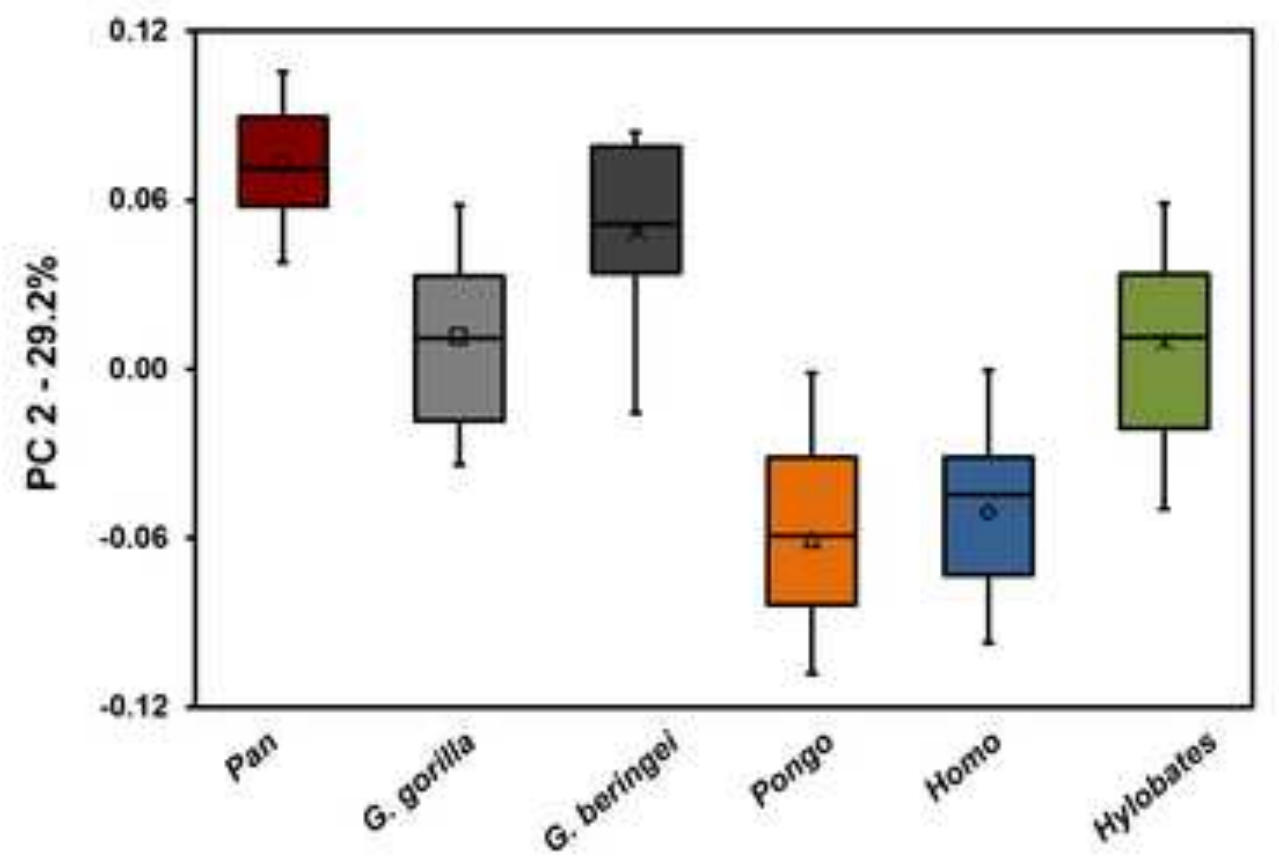

\begin{tabular}{|c|c|c|c|c|c|c|c|}
\hline 4 pt. Wire & PC 2 Moan & Pan & Q. gorilla & a. beringel & Pongo & Howo & Hylobates \\
\hline Pan & 0073 & & 0.06 & 002 & 0.13 & 0.12 & 0.06 \\
\hline G. gorllia & 0.011 & $<0.001$ & & 004 & 0.07 & 0.06 & 0,001 \\
\hline G. beringei & 0050 & 0.57 & 0.08 & & a.t1 & 0.10 & 0.04 \\
\hline Pango & $006 t$ & $.06 .06 t$ & $<0.001$ & $<0.004$ & & 0.01 & $0.0 \mathrm{~T}$ \\
\hline Homo & $-605 t$ & $<0.001$ & $<0.00 t$ & $<0,001$ & ars & & 0.06 \\
\hline Hylabates & 0.010 & $<6.001$ & 1.00 & 005 & $<0.001$ & $<0.004$ & \\
\hline
\end{tabular}




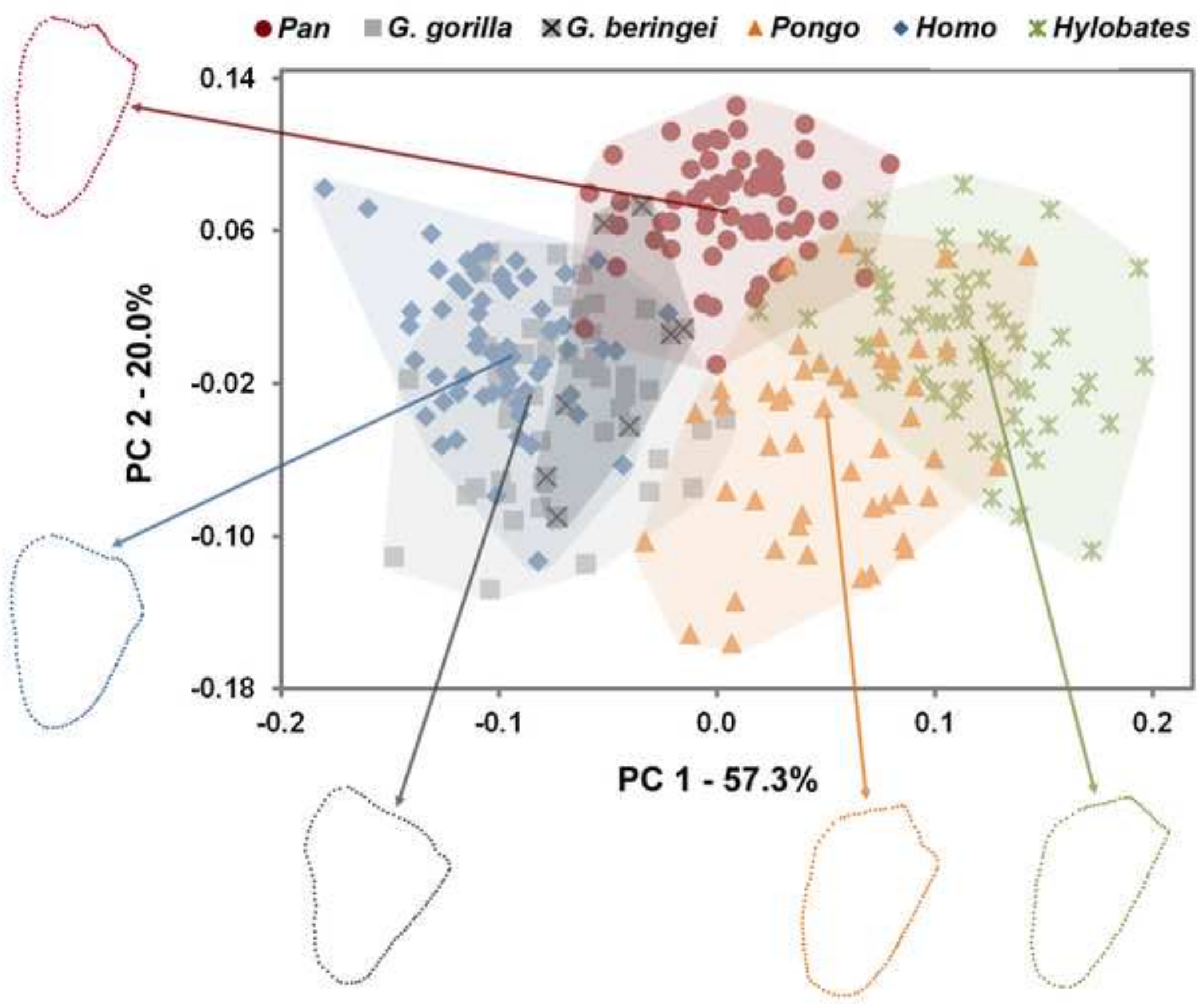




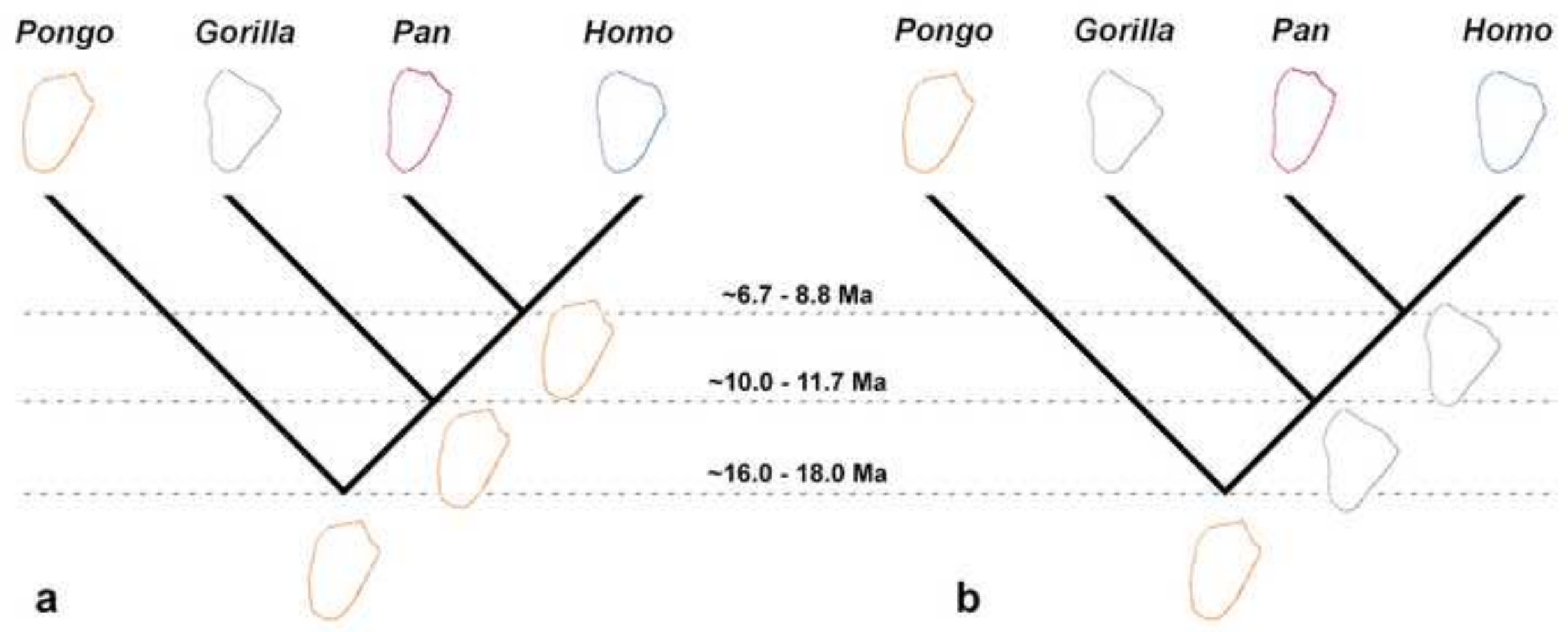

